University of Nebraska - Lincoln

DigitalCommons@University of Nebraska - Lincoln

$11-2020$

\title{
Testing the Hypothesized Antipredator Defence Function of Stridulation in the Spiny Orb-Weaving Spider, Micrathena gracilis
}

Tyler B. Corey

University of Nebraska-Lincoln

Eileen A. Hebets

University of Nebraska-Lincoln, ehebets2@unl.edu

Follow this and additional works at: https://digitalcommons.unl.edu/bioscihebets

Part of the Animal Sciences Commons, Behavior and Ethology Commons, Biology Commons, Entomology Commons, and the Genetics and Genomics Commons

Corey, Tyler B. and Hebets, Eileen A., "Testing the Hypothesized Antipredator Defence Function of Stridulation in the Spiny Orb-Weaving Spider, Micrathena gracilis" (2020). Eileen Hebets Publications. 95. https://digitalcommons.unl.edu/bioscihebets/95

This Article is brought to you for free and open access by the Papers in the Biological Sciences at DigitalCommons@University of Nebraska - Lincoln. It has been accepted for inclusion in Eileen Hebets Publications by an authorized administrator of DigitalCommons@University of Nebraska - Lincoln. 
Published in Animal Behaviour 169 (November 2020), pp. 103-117; doi: 10.1016/j.anbehav.2020.09.003 Copyright (c) 2020 Association for the Study of Animal Behaviour. Published by Elsevier Ltd. Used by permission.

Submitted April 22, 2020; revised June 23, 2020; accepted August 13, 2020; published online October $15,2020$.

Supplemental video is attached to the archive record for this article. (See caption following Appendix.)

\title{
Testing the Hypothesized Antipredator Defence Function of Stridulation in the Spiny Orb-Weaving Spider, Micrathena gracilis
}

\author{
Tyler B. Corey and Eileen A. Hebets
}

School of Biological Sciences, University of Nebraska-Lincoln, Lincoln, Nebraska, USA

Corresponding author - T. B. Corey, School of Biological Sciences, University of Nebraska-Lincoln, 1101 T Street, 323 Manter Hall, Lincoln, NE, 68588, USA, email tylercorey13@gmail.com

\begin{abstract}
The observable diversity of antipredator defenses across organisms demonstrates predation's impact on trait evolution. The functions of many traits that are presumed to have an antipredator function have never been directly tested. The spiny orb-weaving spider, Micrathena gracilis, for example, stridulates when grasped. While stridulation was first hypothesized to be an antipredator defense nearly 50 years ago, no data exist to support this hypothesis. To explore the form and function of $M$. gracilis stridulation, we first quantified the behavioral and acoustical properties of sound production. Next, using laboratory assays, we directly tested the effect of stridulation on survival with an avian predator-blue jays, Cyanocitta cristata. Finally, we conducted a large mark-recapture field study in which we compared the natural survival of experimentally manipulated adult female M. gracilis that could not stridulate (silenced) versus could stridulate (control). Stridulatory pulses produced broadband frequency spectra, consistent with acoustic antipredator defenses in other taxa. We also observed stridulation by male M. gracilis for the first time. In staged laboratory interactions with captive blue jays, we found no differences in survival between silenced and control M. gracilis. Similarly, in our mark-recapture field study, we found no differences in survival estimates between silenced and control groups, nor an effect of stridulation rate. While $M$. gracilis stridulation closely resembles
\end{abstract}


antipredator stridulation in other arthropods, our behavioral data do not yet provide solid support for an antipredator function in $M$. gracilis.

Keywords: antipredator behavior, defensive sound, predator-prey interaction

Many animals produce defensive sounds during predator-prey interactions (reviewed in Caro, 2005; Conner, 2014). Anitpredator defense is achieved through a diversity of mechanisms. For example, prey can startle predators (i.e., deimatism, Umbers et al., 2017) through the production of sudden sounds such as whistling (Bura, Rohwer, Martin, \& Yack, 2011; Dookie, Young, Lamothe, Schoenle, \& Yack, 2017), signal the presence of predators to other members of a social group through alarm calls (Blumstein \& Armitage, 1997; Manser, 2001), and signal the presence of other defensive traits in prey themselves through warning displays (Ratcliffe \& Nydam, 2008; Rowe \& Halpin, 2013). Defensive sounds often produce broadband frequency spectra; it is hypothesized that such broadband sounds should be detectable to predators having sensory systems of varying sensitivity, thus making them effective defensive sounds to multiple potential predators (Masters, 1979). This hypothesis, along with the array of predators' responses to defensive sounds, provides a strong foundation for testing whether certain sound production behavior could function in antipredator defense.

One particularly widespread mechanism of sound and vibration production is stridulation - that is, sound generated by animals rubbing hardened body parts together (arachnids: Alexander, 1958; Hrušková-Martišová, Pekar, \& Gromov, 2008; Pomini, Machado, Pinto-da-Rocha, Macías-Ordóñez, \& Marsaioli, 2010; Shear, 1970; Uhl \& Schmitt, 1996; crustaceans: Chen, Carrasco, \& Ng, 2014; Patek, 2001; fish: Bosher, Newton, \& Fine, 2005; insects: Cocroft, 1999; DeVries, 1990; Keuper \& Kühne, 1983; Lewis \& Cane, 1984; Masters, Tautz, Fletcher, \& Markl, 1983; Roces, Tautz, \& Hölldobler, 1993; Tautz, Roces, \& Hölldobler, 1995). Stridulation requires the coordinated movement of body parts possessing (often) specialized morphology and generally involves the rapid movement of a "pick" against a ridged surface known as a "scraper" (Masters, 1980). The specialized structures associated with stridulation - that is, stridulatory organs - and associated behavior are diverse (spiders: Rovner, 1975; Heteroptera: Polhemus, 1994; spiny lobsters: Patek, 2001; ant nest beetles: Di Giulio, Fattorini, Moore, Robertson, \& Maurizi, 2014).

Stridulation can simultaneously produce sound waves that can travel through air or water, substrate-borne (seismic) vibrations (Cocroft, 1999; Elias, Mason, \& Hebets, 2010) and vibrations detected through direct contact with the stridulating animal (Roces \& Manrique,1995). Additionally, these components can be detected individually or in concert (Keuper \& Kühne, 1983) and by different sensory structures (Hill \& Shadley, 1997). The function of stridulation can also be quite varied, as it is known to play a role in courtship (crickets: Alexander, 1962; homopterans: Roces \& Manrique, 1995; jumping spiders: Elias, Hebets, Hoy, \& Mason, 2005; Schizocosa wolf spiders: Hebets et al., 2013; Rundus, Santer, \& Hebets, 2010), agonistic contests (crickets: Alexander, 1961; Brown, Smith, Moskalisk, \& Gabriel, 2006; crabs: Chen et al., 2014), coordination of social behavior (leaf-cutter ants: Masters et al., 1983, Roces et al., 1993; treehoppers: Cocroft, 1999), foraging (leaf-cutter ants: 
Tautz et al., 1995), and even cannibalism suppression (spiders: Líznarova, Sentenska, Štáhlavsky, \& Pekár, 2018).

Given its acoustic similarity to other defensive sounds (i.e., production of broadband frequency spectra; Masters, 1980), stridulation is also often thought to serve antipredator functions. In support of this defensive function hypothesis, stridulation among some arthropods has been observed in predator-prey interactions and/or when animals stridulate in response to being handled by humans (spiders: Uetz \& Stratton, 1982; katydids: Heller, 1996). Laboratory experiments have additionally shown that stridulation can function in antipredator defense in numerous arthropod taxa-for example, mutillid wasps, water scavenger beetles and round sand beetles (Masters, 1979), passalid beetles (Buchler, Wright, \& Brown, 1981), and spiny lobsters (Bouwma \& Herrnkind, 2009; Staaterman et al., 2009). Stridulation presumably functions in defense by eliciting a startle response in predators, signaling prey unprofitability (i.e., acoustic aposematism) and/or resembling other, dangerous prey that also stridulate (i.e., acoustic mimicry).

Despite the existence of a number of laboratory-based experiments, there is a lack of research testing antipredator functions of stridulation under natural conditions (but see Bouwma \& Herrnkind, 2009). Field-based studies of antipredator defenses are uncommon, likely due to the difficulty in observing and making inferences about predation in nature (but see tethering studies reviewed in Aronson, Heck, \& Valentine, 2001; Barshaw, Lavalli, \& Spanier, 2003; Puntilla, Martin, \& Valentine, 2012). Even fewer studies have examined how manipulations of putative antipredator traits impact prey survival over extended periods (but see Forsman \& Appelqvist, 1999).

In this study, we used manipulations of stridulation production in conjunction with a field-based mark-recapture study and laboratory-based predator-prey interactions to test the proposed antipredator defense function of stridulation in the spiny orbweaving spider Micrathena gracilis.

Micrathena gracilis spiders are commonly found in deciduous forests in North and Central America (Levi, 1978) and were first reported to be able to stridulate 50 years ago (Hinton \& Wilson, 1970). Upon being grasped, adult females engage in a stereotyped movement where they scrape the femurs of their fourth pair of legs against their book lung covers (circular patches of cuticle located on the ventral surface of the abdomen; Hinton \& Wilson, 1970). The scraping of these body parts produces sound that is robust enough to startle human observers (Uetz \& Stratton, 1982). Although readily observed during human-spider interactions, stridulation has not been observed in previous studies exploring $M$. gracilis mating behavior (Bukowski \& Christenson, 1997a; 1997b, 2000), prey capture (Biere \& Uetz, 1981; Vanderhoff, Byers, \& Hanna, 2008), or habitat use and movement patterns (Hodge, 1987a; 1987b). Thus, stridulation in M. gracilis is presumed to have an antipredator function (Cloudsley-Thomspon, 1995; Hinton \& Wilson, 1970; Uetz \& Stratton, 1982). Despite its decades-long presence in the literature, this function has not been directly tested.

In this study, we used a combination of laboratory and field experiments to thoroughly describe stridulation in adult female $M$. gracilis and to directly test its long-hypothesized antipredator defense function. We first quantified adult female $M$. gracilis stridulatory behavior and its acoustic properties. We also report stridulation in adult male M. gracilis for the first time. We then tested the effect of stridulation on adult female M. gracilis handling 
time and survival under laboratory conditions using a model avian predator-blue jays, Cyanocitta cristata-by presenting blue jays with stridulation-silenced (hereafter "silenced") and sham-treated (hereafter "control") spiders. Finally, we explored the impact of stridulation presence/absence on survival of $M$. gracilis in their natural habitat using a long-term markrecapture study with silenced and control adult female $M$. gracilis.

If stridulation has an antipredatory function in M. gracilis, we predicted the following. First, M. gracilis stridulation should be qualitatively similar in its acoustic properties to antipredator stridulation in other arthropods in that it should produce broadband frequency spectra. Second, control M. gracilis should have higher handling time and survival in response to blue jay attacks compared to silenced M. gracilis. Third, control M. gracilis should survive for longer in nature than silenced M. gracilis.

\section{Methods}

\section{Experiment 1: Quantifying Stridulation in Micrathena gracilis}

We developed a laboratory assay to quantify the vibratory, acoustic, and behavioral properties of stridulation in adult female and male M. gracilis.

Collection, maintenance and measurement of Micrathena gracilis

We collected adult $M$. gracilis ( $N=36$ females, 13 males) from their webs in Wilderness Park, Lincoln, Nebraska, USA, during the day and transported them to the University of Nebraska-Lincoln. Once in the laboratory, we kept individual spiders in plastic deli dishes (11.5 cm diameter, $4.5 \mathrm{~cm}$ tall) lined with moist paper towel until we ran them in behavioral assays, which we did the same day as collection. We collected and measured female $M$. gracilis during 10 September-19 September 2017, and male M. gracilis on 24 June and 2 July 2018 (males).

Prior to sound recordings, we measured the mass of each individual using an electric scale (Ohaus Adventurer Pro). We then photographed each individual with a size standard using a Leica MZ16 microscope, an AmScope LED-8WD light source, and a Diagnostic Instruments 14.2 64 Mp Shifting Pixel camera connected to SPOT software (v.5.2, http://www .spotimaging.com/). We photographed each spider from the dorsal, lateral, and ventral views and later measured photographs using ImageJ (Schneider, Rasband, \& Eliceiri, 2012).

We used ImageJ (v.1.52u) to collect size measurements of M. gracilis from microscope photographs. Due to the irregular shape of $M$. gracilis, we used abdomen length measured from the ventral side as our measure of body length.We measured abdomen length as the straight-line distance from the posterior-most point of the medial abdomen to the point where the abdomen meets the pedicel along the M. gracilis midline.

Sound recording set-up

We used a laser Doppler vibrometer and microphone to record sounds produced by stridulating M. gracilis. First, in order to keep the spiders stationary while still allowing all movement necessary for stridulation, we affixed individual $M$. gracilis by their ventral abdomen posterior to their spinnerets to $\sim 4 \mathrm{~cm}$ wooden dowels, using hot glue that had cooled sufficiently to not harm the spiders (Fig. 1). Next, in order to most effectively record 
sounds from stridulating spiders, we applied a small amount of silver paint (Sharpie nontoxic oil paint marker) to the dorsal abdomen of each individual. This silver paint enabled us to focus the laser vibrometer, thus facilitating clear audio recordings.

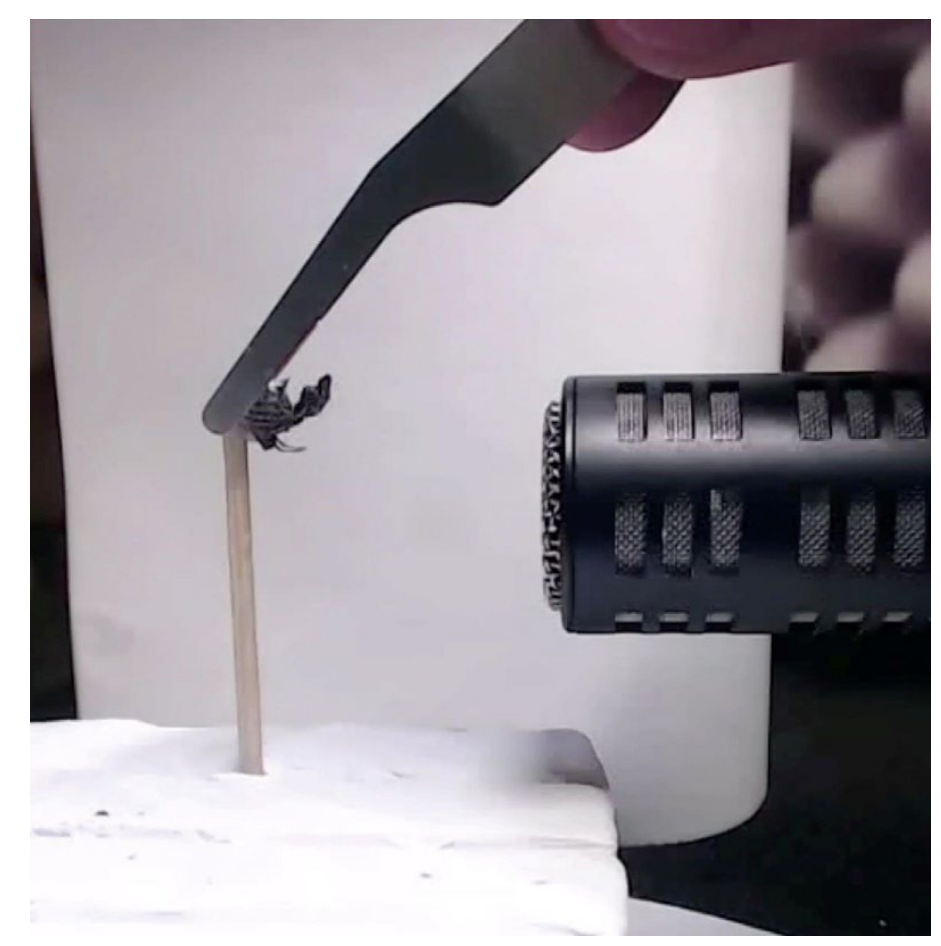

Figure 1. Laboratory assay for quantifying the behavioral and acoustic properties of stridulation in the spider Micrathena gracilis (see also Video S1). A laser Doppler vibrometer is focused on the dorsal abdomen on the M. gracilis, and a microphone is placed $3 \mathrm{~cm}$ from the laser, facing the anterior end of the spider. Here, an experimenter makes contact with an adult female spider using soft forceps.

We placed mounted and painted M. gracilis on their dowels in a brick of plasticine (Sargent Art Non-Hardening Modeling Clay, Gray) inside a $50 \times 37 \times 43 \mathrm{~cm}$ sound-insulated chamber, keeping the top of the spider and the microphone level with each other (Fig. 1, Supplementary Video S1).We lined the chamber with loaded vinyl PSA and soundproof foam (Super Soundproofing Co.) and placed it on a vibration isolation table (Minus K $50 \mathrm{BM}-8 \mathrm{C}$ ). The sound-insulation chamber had a laser Doppler vibrometer (Polytech LDV 100) mounted in the top and a microphone (Sennheiser ME 64, with a TASCAM DR-05 audio recorder) placed on the right side $3 \mathrm{~cm}$ from the laser Doppler vibrometer, to detect airborne vibrations. We mounted one webcam in the top facing down and a second webcam on the left side to provide a side view. The chamber had a door on one side, which we kept open so that we could directly interact with spiders during the assays. With this design, we could simultaneously record the cuticle-borne vibratory component (laser Doppler vibrometer) and the airborne acoustic component (microphone) of stridulation. We 
could also use videos recorded from these two different angles to correlate movements to the production of stridulation and to infer stridulation in some recording, as the audio quality was sometimes relatively poor.

During recordings, we focused the laser Doppler vibrometer on the silver paint marking applied to the dorsal abdomen of each M. gracilis and recorded from the laser Doppler vibrometer through a Focusrite Scarlett Solo audio interface into CaptureSync software (Ben Software, London, U.K., https://www.bensoftware.com/capturesync/). While we could clearly record stridulation using the laser Doppler vibrometer, the airborne sound from the $M$. gracilis that we sampled was surprisingly quiet (see Discussion). We therefore had to increase the microphone audio recorder gain until it was nearly at maximum (90 out of 100 on the TASCAM DR-05) for stridulation to be consistently discernible in microphone recordings. We then kept this input level constant across all trials. We placed a digital stopwatch on the bottom of the laser chamber to match audio and video recording times for later analysis (see Quantifying Stridulation below). We allowed each spider to acclimate for at least 1 min before beginning an assay trial.

\section{Simulated predator attack stimulus}

Through preliminary field observations, we found that M. gracilis appeared to stop stridulating when handled for extended periods. Therefore, we used short, repeated applications of simulated predator attack stimuli to elicit stridulation from $M$. gracilis. Our protocol additionally allowed us to examine the repeatability of stridulatory behavior across multiple stimuli (see Statistical Analyses subsection below).

An individual stridulation trial consisted of four tactile stimulus applications over the course of $1 \mathrm{~min}$. Our assay followed that of prior studies examining potential antipredator stridulation in arthropods (e.g., Pomini et al., 2010; Roces \& Manrique, 1995). For each tactile stimulus, an experimenter (T.B.C.) made contact with the spider's abdomen using a pair of soft forceps (BioQuip Featherweight Forceps, Wide Tip, Rancho Dominguez, California, USA) and gently held the spider for $5 \mathrm{~s}$. No further pressure was added once contact was made. After $5 \mathrm{~s}$, we removed the forceps for $10 \mathrm{~s}$. We repeated this process four times over the course of a $1 \mathrm{~min}$ trial. In some cases $(N=5)$, removing the stimulus caused the spider to become dislodged from its mount, in which case we stopped the assay. For these trials, we were still able to record at least two stimulus applications and thus analyzed two instead of four stimulus applications for the trial. Following behavioral assays, we euthanized spiders by freezing them and then preserved them in $70 \%$ ethanol for future measurement.

\section{Quantifying stridulation}

We used the audio from the laser Doppler vibrometer recordings to quantify stridulation, since they were of higher quality than the microphone recordings. We used the video recordings of trials to validate the presence/absence of a given behavior. For each individual M. gracilis, a scorer (T.B.C.) counted the number of individual stridulatory pulses during each of the four stimulus applications.We scored the presence of stridulation as a binomial response for each individual stimulus application. We scored individuals as having stridulated if they did so during at least one of the complete stimulus applications in a given 
trial. For those individuals that stridulated, we calculated the time to stridulation following the initial tactile stimulus (hereafter "latency to stridulation") as the time from grasping the spider until the first stridulatory pulse. When M. gracilis stridulated, they did so until we removed the stimulus (i.e., after $5 \mathrm{~s}$ ), at which point they immediately ceased stridulating. We calculated stridulation rate as the number of stridulatory pulses performed during a stimulus application, divided by the time that individuals stridulated during that stimulus application.

We visualized acoustic recordings in Raven Lite 2.0.1 (Center for Conservation Bioacoustics, 2016). We generated waveforms and spectrograms from laser Doppler vibrometer and microphone WAV recordings. We qualitatively assessed laser Doppler vibrometer recordings for noise to identify recordings with low noise from the laser to descriptively illustrate the acoustic properties of stridulation ( $N=5$ females). Microphone recordings were band-pass filtered between 1000 and $22000 \mathrm{~Hz}$, due to excessive low-frequency hum and other noise recorded by the microphone. Visualization and preliminary analysis of these spectrograms suggested that this procedure did not exclude any frequencies of stridulation recorded by the microphone.

We graphed waveforms on a shared $Y$ axis within each recording medium (see Results, Fig. 2) for greater clarity in interpreting amplitude. For each recording medium, we standardized waveform amplitudes against the greatest absolute value of amplitude observed in our exemplar recording sample segment relative to the background input signal being sent to the audio recording device. We used the arbitrary amplitude units generated by Raven Lite ("kilounits") when standardizing the axes for these graphs. The maximum amplitude reported for the laser Doppler vibrometer was 18 kilounits, while the maximum microphone amplitude was 1.75 kilounits.We set these maximum amplitude values as 1 and -1 , kept 0 at 0 , and scaled our axes accordingly.

\section{Statistical analyses}

We qualitatively discuss the acoustic properties of the vibratory and airborne sound components of stridulation from female $M$. gracilis for which we had both clean laser Doppler vibrometer and microphone recordings ( $N=3$ females). We present waveforms and spectrograms from these exemplar recordings (Fig. 2). We also qualitatively discuss stridulation by male $M$. gracilis in relation to females and provide a spectrogram recorded using the laser Doppler vibrometer in the Appendix (Fig. A1).

Based on the results of our mark-recapture analyses (see Results, Experiment 3), we explored whether spider mass (log-transformed) could explain variation in stridulatory behavior in response to simulated predator attacks ( $N=36$ adult female $M$. gracilis).We tested the effect of spider mass on the probability of stridulation in a trial (combining all four stimulus applications) using a binomially distributed generalized linear model. We used a likelihood ratio test to compare models with and without mass as a fixed effect (i.e., an intercept-only model). We also used a Gaussian distributed general linear model including spider mass as a fixed effect to predict spider stridulation rates. We included only spiders that stridulated during assays in these analyses $(N=23)$. We assessed the significance of the predictors in these models using $F$ tests (see Results, Experiment 1 ). We describe the mean \pm SD latency to stridulation and stridulation rate for these female $M$. gracilis. We 
calculated the repeatability of latency to stridulation and stridulation rate across the four stimulus applications following Lessells and Boag (1987). We used R v.3.6.1 (R Core Team, 2019) to perform these analyses.

\section{Experiment 2: Laboratory Predator-Prey Interactions}

We performed a laboratory experiment using captive-reared blue jays as candidate predators to test for an effect of female M. gracilis stridulation on survival and handling time in predator-prey interactions. Unfortunately, little is known about the natural predators of M. gracilis, but many birds have been directly observed consuming spiders (California gnatcatcher, Polioptila californica: Burger, Patten, Rotenery, \& Redak, 1999; goldcrests, Regulus regulus: Hogstad, 1984; gray jays, Aphelecoma ultramarine: Riechert \& Hedrick, 1990; eastern meadowlarks, Sturnella magna: Genung \& Green, 1974; willow tits, Poecile montanus, and crested tits, Lophophanes cristatus: Jansson, 1982), and birds have been experimentally shown to have significant impacts on the composition and size of spider communities (Gunnarrson, 2008; Gunnarsson \& Wiklander, 2015). We chose blue jays as our focal predator because blue jays are found at our field site (Wilderness Park, Lincoln, Nebraska, USA) and are known to consume arthropods, including spiders (Cornell Lab of Ornithology, National Audubon Society, https://www.audubon.org/field-guide/bird/blue-jay), and we had access to a captive-reared population of blue jays at the University of Nebraska-Lincoln.

Collection, measurement, and manipulation of Micrathena gracilis

We collected adult female M. gracilis ( $N=40)$ during 25-29 August 2018 and 9-17 September 2018 from Wilderness Park (Lincoln, Nebraska, USA) in the daytime. We recorded the mass of each spider and then photographed each spider using the protocol described ealier (see Experiment 1, Stridulation in M. gracilis).

On a given collection and test day, we sorted the collected $M$. gracilis by mass and sizematched pairs of individuals. We then randomly assigned each individual in a pair to one of two treatments: (1) silenced (i.e., stridulation absent) and (2) control (i.e., stridulation present). We matched silenced and control individuals in order to limit the potential effects of size, mass, and/or condition on predator behavior toward different prey types.

To remove the ability of $M$. gracilis to stridulate (silenced), we used the shaft of a sewing needle to apply beeswax (approximately $2-3 \mathrm{mg}$ per spider) to each book lung cover. In our sham treatment, we applied the same amount of beeswax to two regions on the posterior ventral abdomen (control group) using the same technique. Preliminary trials using recordings from the microphone (and later the laser vibrometer) confirmed that application of beeswax to the book lung covers was sufficient to silence sound production and had no immediately observable adverse effects on behavior and health of M. gracilis or blue jays (see Appendix).

\section{Maintenance of blue jays}

For our focal avian predator, we used a captive population of eight blue jays bred and housed individually at the University of Nebraska-Lincoln Avian Cognition Lab. Birds are given ad libitum water and food (Lafaber's Cockatiel and Parrot Pellets) and kept on a 
14:10 h light:dark cycle. All behavioral trials were conducted during the light phase of the light:dark cycle.

\section{Predation trials}

We transferred individual blue jays to a separate room that contained a test cage with a wooden perch and feeding dish for predation trials (see Results, Fig. 3a).We mounted a Sony HDR-SR10 Handycam to a tripod and placed it over the cage. We mounted a Canon Rebel 6 with a Canon EF-S 18-55 mm lens to a tripod and placed it adjacent to the cage door. To obtain more detailed observations of predator-prey behavior, an experimenter (T.B.C.) was always present in the room recording macro footage throughout each trial using the Canon camera.

Each blue jay went through at least three habituation sessions prior to experimental trials. In these sessions, we transferred birds to the test cage in an isolated room with the aforementioned camera set-up and the experimenter (T.B.C.) present.We kept each blue jay in the testing cage for at least $20 \mathrm{~min}$ and added one mealworm to the feeding cup every $5 \mathrm{~min}$. We did this to acclimate birds to experimental conditions and associate the presence of prey with the testing cage.

We kept both mealworms and spiders in a separate laboratory space adjacent to the testing room in order to prevent birds from detecting potential prey cues. Therefore, the experimenter exited and reentered the testing room between presenting each prey item. Of the eight birds available for us to run in this experiment, only four birds habituated (i.e., consistently ate mealworms) to these experimental conditions. This does not include the bird used to pilot our experimental protocol, which we excluded from data collection trials. We include data from trials with these four birds in our analyses.

We used a repeated measures design with each of our four focal birds. At the start of each trial, we transferred each blue jay to a test cage and allowed it to acclimate for $5 \mathrm{~min}$. We then presented four potential prey items (one silenced M. gracilis, one control M. gracilis, and two mealworms) one at a time, every day, over the course of five consecutive trial days (e.g., four prey/day $\times 5$ days $=20$ prey) to each bird. Thus, over the course of the feeding experiment, we presented each bird with five silenced M. gracilis, five control $M$. gracilis, and 10 mealworms. Our total sample size across all birds then included 20 silenced $M$. gracilis, 20 control M. gracilis, and 40 mealworm feedings. We randomized the order of the prey items presented each day, except that mealworms were always alternated with $M$. gracilis (e.g., randomly assigned $M$. gracilis $\rightarrow$ mealworm $\rightarrow$ randomly assigned $M$. gracilis $\rightarrow$ mealworm). This allowed us to confirm that birds were motivated to take prey during our experiment (i.e., birds not attacking mealworms may indicate lack of motivation to feed) and were not experiencing any distress. These birds were accustomed to receiving mealworms in behavioral experiments and readily consumed them in our experiment.

We placed individual prey items in the feeding cup and in the testing cage at $5 \mathrm{~min}$ intervals. After $5 \mathrm{~min}$, regardless of when/how the individual blue jay interacted with the prey item, we removed the feeding cup from the testing cage. We then cleaned the feeding dish using 70\% ethanol, rinsed it with water, and dried it using paper towel between each prey item to remove potential prey cues. Afterward, we immediately presented the next prey item as just described and repeated this process for each of the four prey items. Thus, 
an individual behavioral trial ran for approximately $30 \mathrm{~min}$, including the $5 \mathrm{~min}$ acclimation period: 20 min of presenting prey and cleaning of the feeding dish between prey items. After we offered all prey items for a given day,we returned the focal blue jay to its home cage.

Scoring predator-prey interactions

For each prey item (i.e., spider or mealworm), we recorded whether the blue jay (1) handled, (2) killed, and (3) ate the prey item. We considered that birds handled a given prey item if they used their beaks to make contact with it at least once during a trial. We confirmed whether prey survived or were killed during a given trial by monitoring intact prey until at least $24 \mathrm{~h}$ after the trial and checking whether prey could still move normally. We considered a spider to have been eaten by a blue jay if less than $50 \%$ of the spider's exterior cuticle was left following the blue jay's attack(s). We made this distinction because most $M$. gracilis in both treatment groups were crushed and subsequently abandoned by birds (see Results).

We also recorded (1) the time until a blue jay attacked a prey (i.e., latency to attack), (2) the handling time of prey by birds, and (3) the number of times that birds dropped (and picked back up) the prey before they stopped handling them. We measured the latency to attack prey as the time (in seconds) from a prey item being added to the experiment cage in a feeding cup until the time at which a blue jay first made contact with the prey using its beak. We defined handling time as the time from when birds first made contact with prey using their beak until the last time that they made contact using their beak in a given trial. Therefore, handling time lasted until the prey was either eaten or abandoned. We measured the number of times that birds dropped a given prey item by counting every time that a blue jay, which had been holding a prey item in its beak, dropped it onto a surface (e.g., the food cup, the perch, the cage bars).

\section{Statistical analyses}

We analyzed blue jay behavior toward prey of each type (stridulation-silenced M. gracilis, control M. gracilis, and mealworms) using repeated measures analyses of variance (ANOVAs) for Gaussian data (latency to attack and handling time, both log-transformed). In each model, we examined the effect of prey type on a given response variable, and specified predator identity (ID) as the experimental block to control for the repeated measure of individual birds. We used Tukey's honest significant difference (HSD) post hoc tests on our repeated measures ANOVA to perform pairwise comparisons between prey types. We removed one outlier from our latency to attack analyses, in which a blue jay attacked a control M. gracilis after 293 s. Because of this, and three occasions when a bird never attacked the prey items that we offered (one silenced M. gracilis and two control M. gracilis), our estimates from the repeated measures ANOVAs are biased due to differences in sample sizes across treatment groups.

We were unable to fit binomially distributed statistical models to analyze differences in the probability of birds handling and killing different prey types, since birds handled and killed nearly every prey item that we presented to them (see Results, Fig. 3d, f). Birds also consumed every mealworm that we presented to them (see Results, Fig. 3f). We 
therefore analyzed only potential differences in the probability that birds consumed silenced and control female $M$. gracilis using a binomially distributed generalized linear mixed model. In this model, we included prey type (silenced and control M. gracilis) as a fixed effect and predator ID as a random effect specifying random intercepts in order to control for the repeated measures of individuals.

\section{Experiment 3: Field Mark-Recapture Study}

To explore the potential beneficial function of stridulation in nature, we conducted a markrecapture study in the field using silenced and control adult female M. gracilis.

Field site

We established a $100 \mathrm{~m}$ transect through deciduous forest in the southernmost region of Wilderness Park (Lincoln, Nebraska, USA) in an undisturbed area of the forest obscured from public trails (GPS coordinate: $40^{\circ} 41^{\prime} 57.8^{\prime \prime} \mathrm{N} 96^{\circ} 41^{\prime} 09.0^{\prime \prime} \mathrm{W}$ ). The habitat consisted primarily of tall understory vegetation with small trees, although several larger trees and areas lacking understory vegetation were also present in the transect.

\section{Marking protocol}

We surveyed our transect for adult female M. gracilis during 0600-2000 hours from 8 August to 22 August 2017. Our survey area included a $3 \mathrm{~m}$ span, at and below eye level, on each side of the transect where we collected each $M$. gracilis by hand.

Given that we observed interindividual variation in both the likelihood to stridulate and stridulation rate (see Results, Experiment 1, Quantifying stridulation in M. gracilis), we collected data on each field-marked spider's stridulatory behavior prior to their stridulation manipulation. To do this, we gently held the spider by the abdomen and used a hand-held clicker to count each time an individual stridulated during a $1 \mathrm{~min}$ period.We recorded the audio of these assays using a headset microphone (Bose SoundSport in-ear headphones) into a voice-recording smartphone application (Apple iOS Voice Memos) for later analysis. We recorded ambient temperature at time of capture using a Kestrel 3000 Weather Meter. We had 11 missing temperature values, for which we used the next closest temperature measurement in time, all of which were within 45 min of each other.

Following this assay, we measured each spider's mass using a portable Ohaus Scout Pro Balance. We also photographed all spiders with size and color standards using a Ricoh WG-4 digital camera in $1 \mathrm{~mm}$ macromode, with additional lighting from two clip-on LED reading lights. Next, we assigned each spider to a stridulation treatment (silenced or control). We systematically alternated assigning encountered $M$. gracilis to each of the two treatment groups prior to capture so we assigned each individual blind to potential covariates.

We then manipulated the spiders according to their assigned treatment. For silenced spiders, we applied clear nail polish (Sally Hansen Quick-dry 101, Sally Hansen, Inc., New York, New York, USA) to each book lung cover (see Appendix for preliminary data on efficacy of treatment and survival and health of spiders following treatment). For control spiders, we placed the same nail polish on two equivalently sized areas on the posterior ventral abdomen. We used the shaft of a sewing needle to perform all applications of nail 
polish. We used nail polish for manipulations in the field rather than beeswax because we could not reliably melt and apply beeswax at our field site.

Finally, we applied paint markings to each spider to the peripheral sides (distal segments) of the fourth pair of legs using Sharpie nontoxic oil paint markers to identify individual spiders during resighting surveys. We used unique colors to represent the numbers zero through nine, and marked the left and right legs (fourth pair, ventral view) of each spider with the colors representing the tens and ones digit of its identification code, respectively (e.g., individual 10 was marked with red and white paint on its left and right fourth legs, respectively). Due to degradation of markings over time, we reapplied these markings during resighting surveys in the fourth week of this experiment.

After each spider was measured, manipulated, and marked, we placed it in a deli dish lined with paper towel for at least $1 \mathrm{~min}$ to ensure that it could still walk normally. We then released each $M$. gracilis where we collected it, either onto its web (if the web was still intact) or at one of its web attachment points on vegetation. We marked spider locations with flagging tape labeled with the spider's identification markings and the time and date of capture. We tied flagging tape around a piece of vegetation to which the web was attached, either at the base of branches (close to trunk/joint), or around the stem of the plant if branches were not nearby.

\section{Recapture surveys}

One experimenter (T.B.C.) performed resighting surveys over the course of 7 weeks (10 August-23 September 2018). Each week, a total of six resighting surveys were performed (two per day for three consecutive days). These resighting surveys were distributed in time to best cover the active cycle of $M$. gracilis based on our preliminary observations (08002200 hours). Surveys lasted for approximately $90 \mathrm{~min}$ on average, with time spent surveying decreasing over the course of the experiment because of the seasonal decline in the adult spider population (Bukowski \& Christenson, 1997b). We visually surveyed for $M$. gracilis silk, using a Maglite ML300L LED flashlight and Black Diamond ICON IPX7 headlamp to illuminate silk and spiders, regardless of time of day.

We used previously flagged locations of spiders as starting points in surveys, searching around every piece of vegetation that had been flagged and every adjacent piece of vegetation. If an individual moved and we could not find it on its web or on the flagged or adjacent vegetation, we added a new flag to a piece of vegetation that the new web was attached to. During the fourth week of surveys, we began using a telescoping pool sifter (2-4 $\mathrm{m}$ long) to reach spiders from webs higher in the canopy. However, we do not believe this led to relevant differences in resighting frequency of marked spiders, as we only recaptured five marked spiders in this way across 24 resighting surveys.

\section{Statistical analyses}

Before estimating survival and resighting probabilities of M. gracilis over the course of our experiment, we first analyzed potential differences between treatment groups (silenced versus control) in mass, body size, condition, and stridulation rate at capture in order to confirm that potential differences in these covariates across groups did not bias our inferences about survival. We measured condition as the residual mass (i.e., the residuals of a 
linear model with log-transformed body length as the predictor and log-transformed mass as the response). We used Welch's two-sample $t$ tests to compare mass (log-transformed) and condition across groups because these variables were normally distributed. We used Wilcoxon rank sum tests to compare body size and stridulation rate across groups because these variables were not normally distributed (even after being log-transformed).

There were no significant differences in mass ( $t$ test: $\left.t_{111.6}=0.009, P=0.993\right)$, abdomen length (Wilcoxon rank-sum test: $W=1678, P=0.76$ ), condition ( $t$ test: $t_{106.8}=-0.654, P=0.514$ ), or stridulation rate (Wilcoxon rank-sum test: $W=1742, N=114, P=0.47$ ) of female $M$. gracilis across our silenced and control treatment groups. Approximately half of the spiders in our field study stridulated within $5 \mathrm{~s}$ of being captured from their webs ( $N=52$ of $114 \mathrm{M}$. gracilis), and there were no significant differences in the proportion of individuals that stridulated in the silenced and control treatment groups (chi-square test: $\chi^{2}{ }_{1}=0.035, P=0.851$ ).

We estimated survival and resighting probabilities of $M$. gracilis over the course of our experiment by analyzing resighting histories using Program MARK software (v.9.x, White, 2020). We used a Cormack-Jolly-Seber (CJS) open design model. This model assumes that the population is open to immigration, emigration, births, and deaths throughout the course of the experiment (Lebreton, Burnham, Clobert, \& Anderson, 1992). We used Akaike's information criterion corrected for small samples (AICc) to identify the model that explained the greatest amount of variation given the fewest parameters. All model parameters were estimated using a logit link function, which were back-transformed in MARK to provide probability estimates on a zero to one scale (see Results, Fig. 4).

We estimated parameters for survival (the probability that individuals survive from one time step to the next) and resighting (the probability that individuals are found on resighting surveys between time steps, given that they are alive), which can be functions of time and/or treatment group, or neither. That is, we specified whether the survival and/or resighting parameters were estimated at each time step (i.e., parameter estimates could change over time) or whether the parameter estimate was held constant throughout the course of the study (i.e., survival/resighting parameter(s) did not change over time). In addition, we tested for an effect of stridulation on survival and resighting estimates by including the treatment group in model structures (i.e., estimating the survival and/or resighting parameter(s) for silenced and control groups separately, rather than for the entire study sample). This allowed us to directly test the antipredator defense hypothesis, by evaluating whether survival estimates differed between silenced and control treatment groups.

We also examined whether mass, body size (measured in abdomen length), condition, or stridulation rate affected parameter estimates across time steps and/or treatment groups, where relevant. Prior to being included in models, all covariates were standardized using $z$ transformations, such that each covariate had a mean value of $0 \pm 1 \mathrm{SD}$. We restricted our model selection to include at most only one individual covariate per model, to keep the model selection process tractable, and because our main focus was testing the hypothesis that survival probability differed between treatment groups.

We had no reason a priori to expect differences in the resighting parameter between our treatment groups that were not due to differences in survival. However, to control for the potential effect of resighting on survival estimates, we performed additional analyses 
using our best model for survival, holding constant those parameters that affected survival and varying the parameters that affected resighting.

We also explored natural variation in $M$. gracilis stridulatory behavior in the field (presence and rate of stridulation in female $M$. gracilis) for comparison with our laboratory assay, in order to validate that our laboratory assay was representative of natural stridulatory behavior. We measured stridulation rate upon capture (prior to experimental manipulation) from our field assay recordings as the number of stridulatory pulses within $5 \mathrm{~s}$ of capturing a spider by counting the number of counter clicks in our field audio recordings. Given the high speed of stridulation and the measurement error from human reaction time, we make only qualitative comparisons between our field and laboratory stridulation assays.

Based on the results of our mark-recapture analyses (see Results, Experiment 3), we tested for a potential effect of mass on stridulatory behavior to explore whether the relationship between mass and survival could be explained by an association of mass and stridulatory behavior. We used a binomially distributed generalized linear model with the probability of stridulating within the first $5 \mathrm{~s}$ of capture as the response variable and spider mass (log-transformed) as the predictor variable. We compared this model to an interceptonly model using likelihood ratio tests (see Results, Experiment 3).

\section{Ethical note}

Collections of spiders (M. gracilis) and our long-term mark-recapture field study were conducted in Wilderness Park (Lincoln, Nebraska, USA) under a standard Wilderness Park Access Agreement issued and notarized by Lincoln Parks \& Recreation. This permit was issued following approval of our experimental protocol.

We developed an experimental manipulation to prevent sound and vibration production from stridulation by the spiny orbweaving spider, M. gracilis. When piloting this manipulation, we kept spiders in individual deli dishes lined with moist paper towel for $24 \mathrm{~h}$ in order to monitor any adverse effects on behavior or health of M. gracilis. We did not proceed with implementing our manipulations until we confirmed that spiders behaved normally after $24 \mathrm{~h}$.

Our laboratory experiment using blue jays as focal predators was conducted under the University of Nebraska-Lincoln Institutional Animal Care and Use Committee Project ID 1666. Blue jays received enrichment through regular contact with human caretakers and the introduction of novel prey during the experiment. We used five of these blue jays (one blue jay when conducting pilot trials, four blue jays for data collection trials) in our study, which successfully habituated to the conditions of our laboratory experiment. In pilot trials, we closely monitored each blue jay immediately after it consumed $M$. gracilis without beeswax, and later with beeswax added, in order to make sure that the prey and/or the manipulation did not cause gastrointestinal distress. We used only 2-3 mg of beeswax per spider to perform experimental manipulations. We did not proceed with data collection trials until we confirmed that a complete experimental trial with our pilot blue jay did not lead to any gastrointestinal distress or abnormal behavior for the bird for at least $24 \mathrm{~h}$.

While we had the option to continue attempting to habituate the remaining birds to experimental conditions, we chose not to, since the data from our four experimental trials produced clear patterns relevant to our research questions (see Results, Experiment 2). 
Running additional birds in these experiments would have meant sacrificing an unnecessary number of additional spiders and mealworms. Prior studies that investigated the effects of arthropod defensive sounds on avian predators, published in Animal Behaviour, had a sample size of four birds (Buchler et al., 1981).

\section{Results}

\section{Experiment 1: Quantifying Stridulation in M. gracilis}

\section{Stridulatory behavior}

Micrathena gracilis stridulate in individual pulses by flicking their prosoma (anterior-most body part) dorsoventrally (Video S1) and scraping the interior of the fourth femur against the ridged surfaces of their book lung covers on their opisthosoma (posterior-most body part) (Hinton \& Wilson, 1970). This movement is fast-an individual pulse occurs within $0.1 \mathrm{~s}$ (Fig. 2). Approximately $64 \%$ of adult female $M$. gracilis ( $N=23$ of 36$)$ stridulated when grasped in this assay.

Spider mass did not predict the presence of stridulation in response to simulated predator attack $\left(\chi^{2}{ }_{1}=-0.319, P=0.5721\right)$, nor did it predict the latency to stridulation $\left(F_{1,22}=\right.$ $0.002, P=0.966)$ or rate of stridulation $\left(F_{1,22}=0.447, P=0.511\right)$ for those spiders that did stridulate. The mean latency to stridulation was $2.5 \pm 1.48 \mathrm{~s}$, and the mean \pm SD rate of stridulation was $1.4 \pm 1.31$ pulses/s. Both latency to stridulation and stridulation rate were highly repeatable within trials across an individual's stimulus applications ( $\sim 62$ and $67 \%$, respectively).

\section{Stridulation form}

An individual stridulatory pulse creates a couplet-one louder "downstroke" and a quieter "upstroke" as the cephalothorax is flicked dorsoventrally. These pulses produce broadband frequency spectra for both cuticle-borne vibrations and airborne sound (Fig. 2). The frequency spectra produced by stridulation is qualitatively similar within individuals across pulses and across both female and male M. gracilis. 

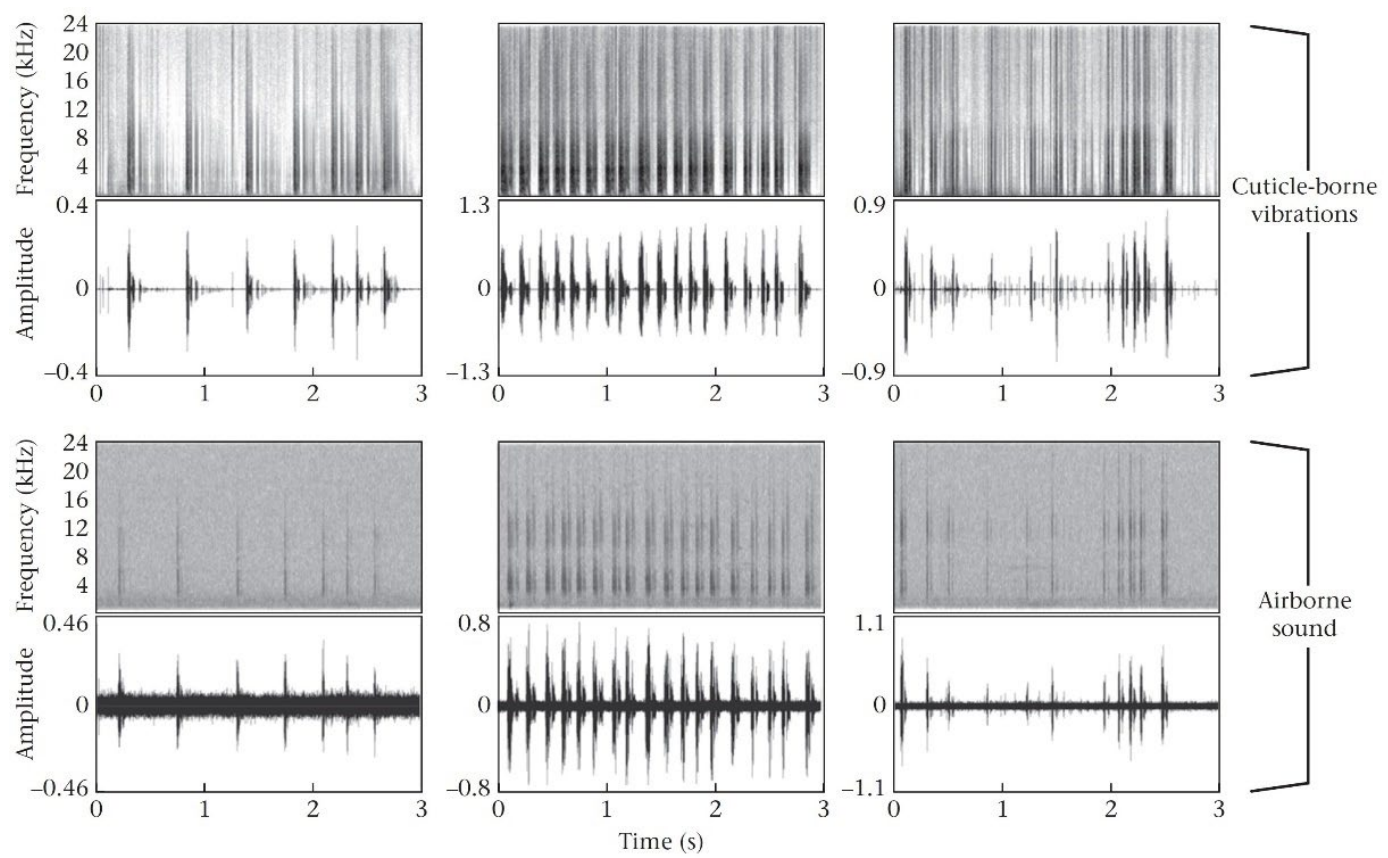

Figure 2. Exemplar spectrograms (top graph in each pair) and waveforms (bottom graph in each pair) of adult female Micrathena gracilis stridulation ( $N=3$ females). We simultaneously recorded cuticle-borne vibrations (using a laser Doppler vibrometer) and airborne sound (using a microphone) produced by stridulation. Recordings are aligned vertically to show spectrograms are measured in kilohertz $(\mathrm{kHz})$. Waveforms are graphed on a shared $Y$ axis within each recording medium. For each recording medium, we standardized waveform amplitudes to the largest absolute value of the amplitude, relative to the background signal being sent to the audio recorded (see Methods for details). Microphone recordings were band-pass filtered between 1 and $24 \mathrm{kHz}$ due to excessive lowfrequency laboratory noise, which is still apparent in waveforms of airborne sound.

\section{Experiment 2: Laboratory Predator-Prey Interactions}

Blue jays' latency to attack was significantly shorter for mealworms than for silenced $M$. gracilis $\left(t_{71}=-3.451, P=0.003\right)$, but there was no significant difference in their latency to attack mealworms and control $M$. gracilis $\left(t_{71}=1.269, P=0.418\right)$ or silenced $M$. gracilis and control M. gracilis ( $t_{71}=-1.777, P=0.185 ;$ Fig. $\left.3 b\right)$. Handling times were significantly shorter for mealworms than for silenced $M$. gracilis $\left(t_{71}=-7.114, P<0.001\right)$ and control $M$. gracilis $\left(t_{71}=6.953, P<0.001\right)$, but there was no significant difference in handling time for silenced $M$. gracilis and control M. gracilis ( $t_{71}=-0.012, P=1.0$; Fig. $3 c$ ). Birds often dropped prey and picked them back up, which affected their handling times of prey. Birds dropped mealworms significantly fewer times than they dropped silenced M. gracilis $\left(t_{71}=-6.040, P\right.$ $<0.001)$ and control M. gracilis $\left(t_{71}=3.955, P<0.001\right)$ while handling them, but there was no significant difference in the number of times that birds dropped silenced and control $M$. gracilis $\left(t_{71}=-1.696, P=0.214\right)$. 
The proportions of each prey type handled by birds were nearly the same (Fig. 3d), as were the proportions of each prey type killed by birds (Fig. 3e). Birds killed every prey item that they handled. While birds then consumed every mealworm that they had handled, they consumed only approximately $45 \%$ of silenced $M$. gracilis and $35 \%$ of control $M$. gracilis (Fig. 3f). There was no significant difference in the proportion of silenced and control $M$. gracilis consumed by birds $\left(\chi^{2}{ }_{1}=0.724, P=0.395\right)$.
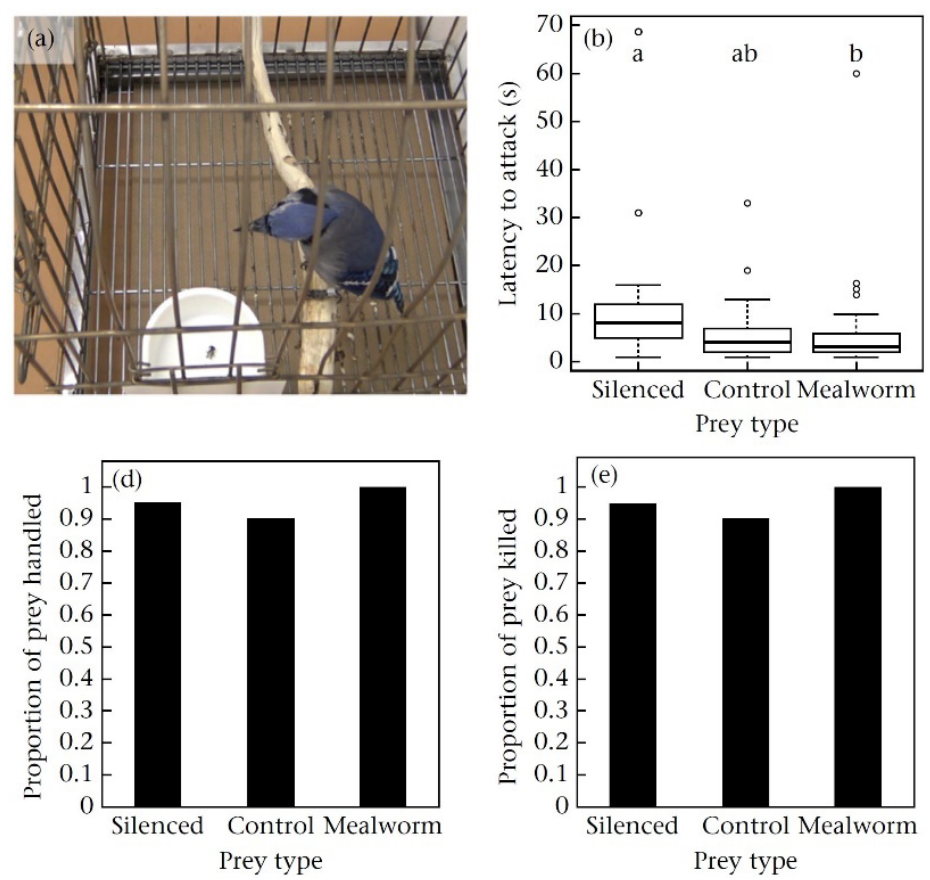

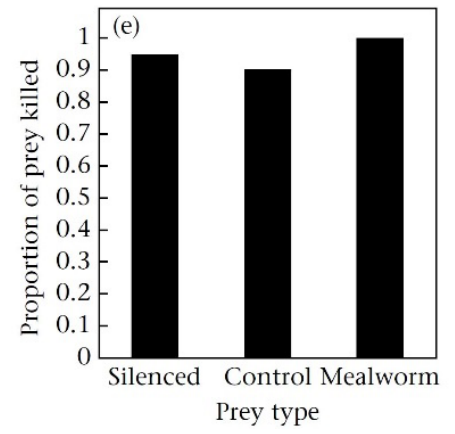

Figure 3. Laboratory predator-prey interactions with blue jays, Cyanocitta cristata ( $N=4$ individuals) with stridulation-silenced and control (sham-treated) female Micrathena gracilis, and mealworms as a positive control for hunger motivation $(N=20$ stridulationsilenced M. gracilis, 20 control M. gracilis, 40 mealworms). (a) Blue jay in testing cage with female $M$. gracilis in feeding cup. (b) Latency to attack and (c) handling time of each prey type. Box plots show $25 \%$ and $75 \%$ quartiles (boxes), medians (lines in the boxes), outermost values within the range of 1.5 times the respective quartiles (whiskers) and outliers (circles). Treatments sharing the same letter did not differ significantly $(P>0.05)$. Proportion of $M$. gracilis prey in silenced and control groups versus the proportion of mealworm prey that were (d) handled, (e) killed, or (f) killed and eaten by blue jays.

\section{Experiment 3: Field Mark-Recapture Study}

\section{Survival and resighting estimates}

Using AICc model selection, we found that the best model for estimating survival of adult female $M$. gracilis specified weekly survival probability as a function of spider mass at capture, with survival probability varying at each time step (Table 1). We found no support for models including treatment group, nor stridulation rate, in estimating survival 
probability. In other words, we found no support for differences in survival between silenced and control M. gracilis. Survival continually decreased after week 3 of the experiment, until we only found 6 of 116 marked M. gracilis during week 7 surveys (Fig. 4a).

Table 1. Cormack-Jolly-Seber models for estimating survival and resighting probabilities of adult female M. gracilis in stridulationsilenced $(N=57)$ and control $(N=57)$ treatment groups across a 7-week mark-recapture study

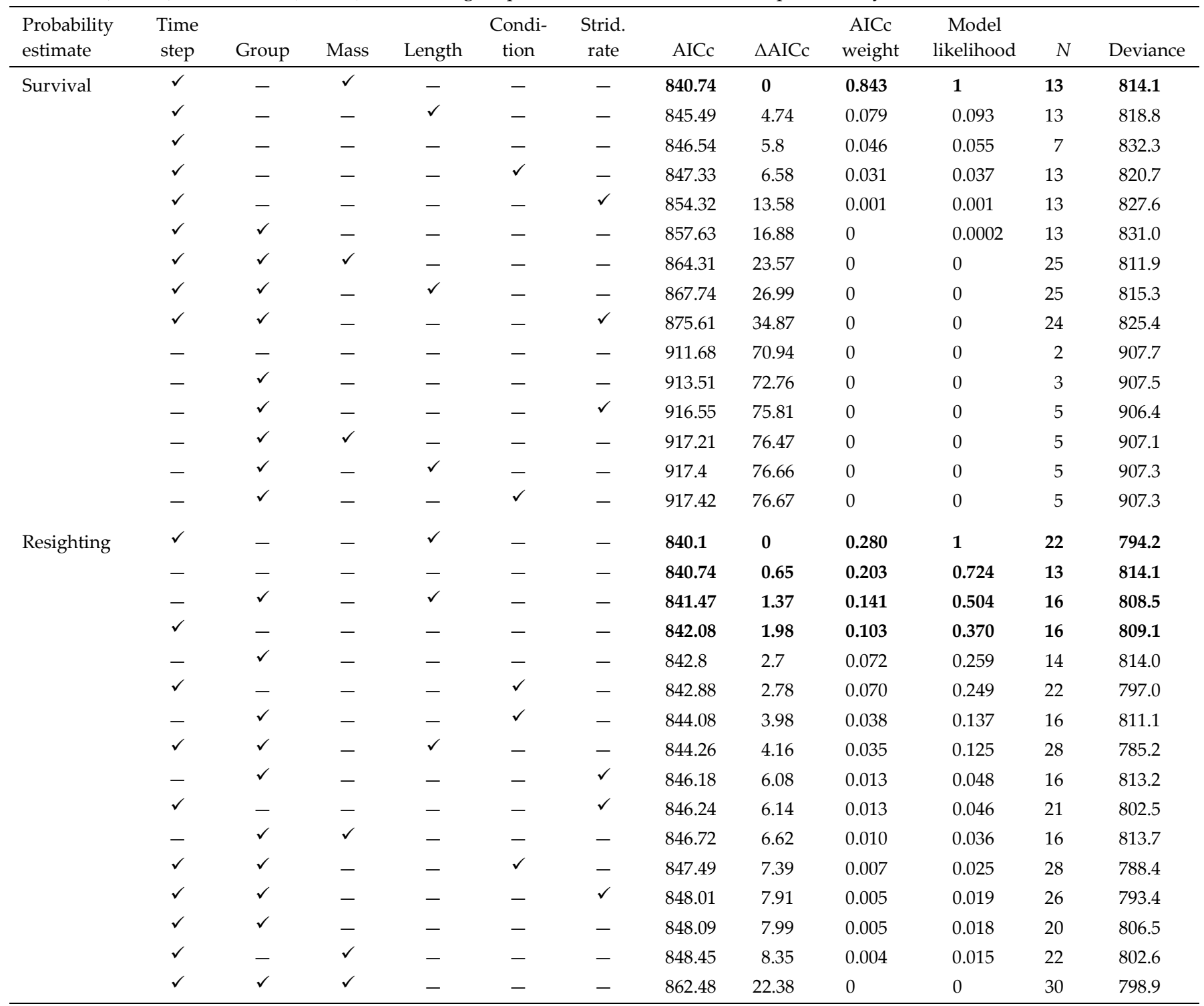

Parameters can be estimated as a function of time steps across sampling weeks, treatment group and/or individual covariates. Check marks indicate columns where parameter estimates are a function of a given predictor. We first evaluated models for predicting survival estimates while holding the resighting parameter constant across time and treatment group, without including individual covariates. We then kept the survival estimate structure of this top model constant while evaluating a model structure for estimating resighting probability. See Methods for details. $N$ = number of model parameters. Bold rows represent the top-ranking model structures for estimating the survival and resighting parameters. 
We found four model structures with similar support (within $\triangle \mathrm{AICc}<2$; Anderson, 2008) for estimating the resighting probability of $M$. gracilis in our study (Table 1 ). We report weekly resighting probabilities from the best model (Fig. $4 \mathrm{~b}$ ), which were a function of spider body size. The size of confidence intervals increased throughout the course of the study.
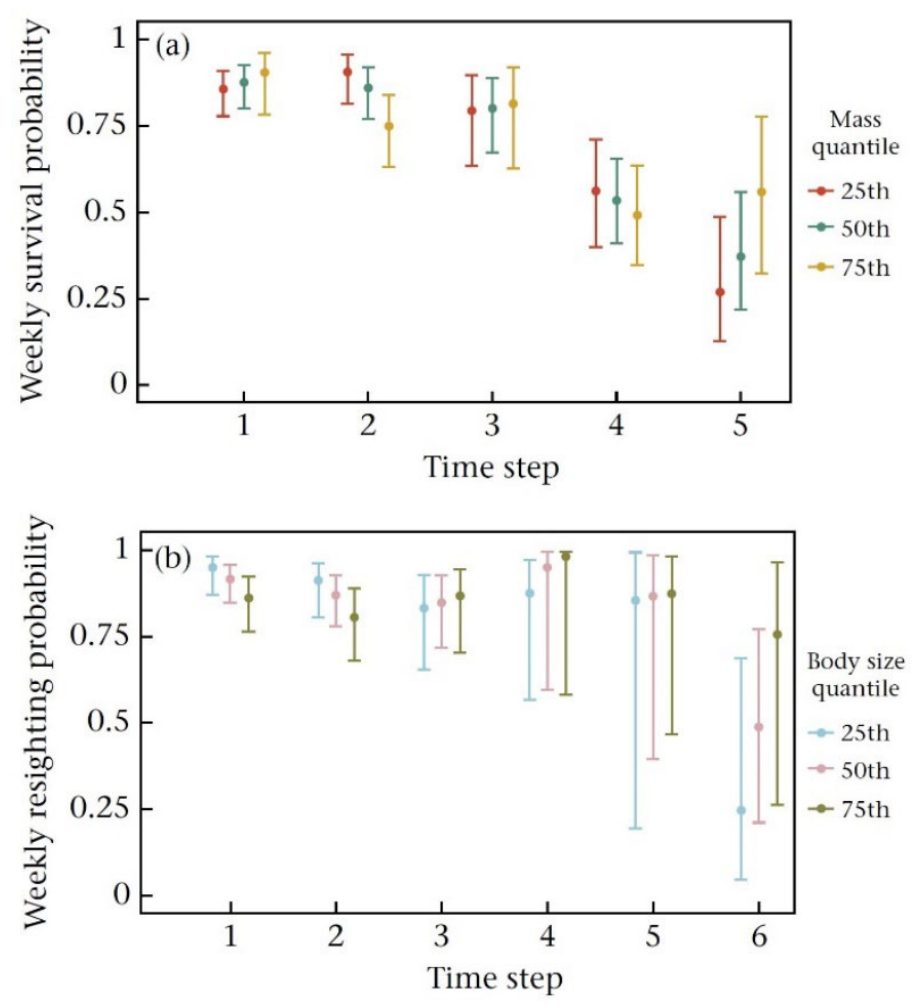

Figure 4. The weekly (a) survival probability and (b) resighting probability of marked adult female Micrathena gracilis ( $N=114$ spiders) in a 7-week mark-recapture study, as estimated using our best supported Cormack-Jolly-Seber model (see Table 1). Both weekly survival probability and resighting probability were estimated at each time step (moving from one week to the next week in our mark-recapture study). Weekly survival probability was a function of spider mass at first capture, while weekly resighting probability was a function of spider body size. We present weekly survival and weekly resighting probability estimates based on the 25th, 50th, and 75th quantiles of (a) spider mass and (b) spider body size, respectively, while holding all other covariates at their median values. Survival probability for the final study time step (time step 6) could not be estimated using Cormack-Jolly-Seber models.

\section{Stridulatory behavior}

Only $45.6 \%$ of adult female $M$. gracilis stridulated within $5 \mathrm{~s}$ of being captured from their webs ( $N=52$ of 114 spiders). The mean \pm SD stridulation rate for spiders that stridulated was $1.1 \pm 0.78$ pulses/s. We found no effect of spider mass on the probability of stridulation 
$\left(\chi^{2}{ }_{1}=-0.143, P=0.705\right)$ or on stridulation rate for spiders that stridulated $\left(F_{1,113}=0.833, P=\right.$ $0.366)$.

\section{Discussion}

We provide the first formal description of the acoustic and behavioral properties of stridulation in adult female and male M. gracilis, and the first tests of its long-hypothesized antipredator defense function. We found that stridulation produces broadband frequency spectra that are similar between individuals, but that individuals differ in the probability of stridulating, latency to stridulating, and rate of stridulating in response to a simulated predator attack. Although these findings are consistent with defensive sounds in other animals (Masters, 1980), our laboratory and field experiments found no support for an antipredator defense function of stridulation. We found no differences in attack or kill rates between silenced and control spiders in live predator-prey laboratory trials with blue jays, and in our field-based mark-recapture study, we found no differences in survival between silenced and control M. gracilis. While our results do not necessarily rule out a potential antipredator defense function of stridulation, we suggest that stridulation could function in conjunction with other potential defenses in adult female M. gracilis-specifically, their thickened and spined abdominal cuticle.

Given the legacy of adult female $M$. gracilis stridulation in the literature, not only were our experimental results surprising, but so was the nature of stridulation itself. In the first description of stridulation and stridulatory organs in M. gracilis, Hinton and Wilson (1970) stated, quite strikingly, "the sound produced by M. gracilis is audible to humans at a distance of about two feet." This is rather substantial, especially given that adult M. gracilis themselves may be at most $10 \mathrm{~mm}$ long. Uetz and Stratton (1982) later noted that $M$. gracilis stridulation is robust enough to startle human observers. It was unclear, however, whether this startling was due to the "feel" of stridulation in one's fingers, or the loudness of the sound itself through air. In contrast to these earlier reports, we needed to hold all of the spiders in our current study immediately next to an observer's ear in order for stridulation to be heard. This includes spiders from our main study site as well as from female $M$. gracilis collected from neighboring sites in Nebraska and from more distant sites in southwestern Kentucky and Mississippi (T. B. Corey, personal observation). Following experience with multiple stridulating spiders, we could better recognize when individuals were stridulating by the vibrations felt through one's fingers or by watching spiders flick their cephalothoraxes while stridulating. The spiders described by Hinton and Wilson (1970) were collected from Mexico, suggesting that the intensity of stridulation by adult female M. gracilis may vary between populations.

Why we observed such dramatic differences in the robustness of stridulation compared to previous studies is unclear. Female $M$. gracilis sampled in prior studies differed in size from the spiders that we observed, which could explain differences in the acoustic properties of stridulation (Bennett-Clark, 1998). Female M. gracilis are also polymorphic in coloration in some parts of their range (Bradley, 2012), which may affect acoustic properties of stridulation if these traits function together in defense (see below). Since M. gracilis can be found in eastern North America from as far north as Maine to as far south as Panama 
(Levi, 1978), future studies could investigate whether differences in local environmental factors (e.g., presence and abundance of different predator types) across this broad geographical range affect differences in selection on potential antipredator defenses (Large \& Smee, 2013; Toju \& Sota, 2006).

Adult female M. gracilis from within our study population varied in their probability of stridulating, latency to stridulating, and rate of stridulating in both our laboratory and field assays.We explored whether the correlation between spider mass at capture and survival in our mark-recapture study could explain some aspects of stridulatory behavior in our field and laboratory assays and found no support for a relationship between size and stridulatory behavior. Stridulatory behavior could instead vary with other traits that we did not quantify in this study. In other animals, for example, stridulation and similar mechanisms of sound/vibration production function in conjunction with other putative defense traits, such as conspicuous and/or cryptic coloration, armored body parts, and/or chemical defenses (Rowe \& Halpin, 2013). Therefore, rigorously quantifying between-individual variation in traits such as coloration, spination, abdomen sclerotization, and abdomen shape and linking these traits to predator-prey interactions and stridulatory behavior could provide a more holistic understanding of potential antipredator defense in M. gracilis.

When using captive blue jays as predators, we found no significant differences in survival and handling time of adult female $M$. gracilis given stridulation-silencing or control treatments. In fact, the number of $M$. gracilis in each treatment group that were killed and eaten by these birds were similar. From this, we may conclude that stridulation alone does not increase the probability that adult female $M$. gracilis survive an encounter with a blue jay and may not affect survival during predator-prey interactions with similar avian predators in nature. However, we recognize several important aspects of the design of this laboratory experiment while interpreting our results.

First, $M$. gracilis are orb-weaving spiders, and in the laboratory these spiders were presented without their webs. Webs can function as an early warning system for spiders of predator attack (Cloudsley-Thompson, 1995), and the posture and orientation of M. gracilis on their webs may limit the extent to which avian predators can attack from an effective angle (Levi, 1978). Second, despite filming all trials with a macro lens, we could not directly observe M. gracilis stridulating, or attempting to stridulate, at any point in the experiment. Therefore, the possibility exists that $M$. gracilis did not (or could not) stridulate when attacked by birds. If so, then we should expect no differences in survival between silenced and control M. gracilis, as we observed in this experiment. Third, the beeswax applied to $M$. gracilis could have rendered the spiders unpalatable to birds and made the birds less likely to consume the spiders. However, we observed similar proportions of $M$. gracilis consumed relative to those killed by blue jays during subsequent experiments in which we did not apply beeswax to spiders (T. B. Corey, personal observation). Given these qualifications with our laboratory experiment, our results clearly show that there were no differences in survival between silenced and control adult female $M$. gracilis with blue jays as predators.

Regardless of how stridulation may or may not function in predator-prey interactions, our laboratory observations suggest that adult female $M$. gracilis may be unprofitable prey for avian predators, and perhaps for other predator types, in nature. Given that we 
observed each blue jay repeatedly pick up and drop most $M$. gracilis multiple times onto the cage's feeding cup or perch, $M$. gracilis require extensive handling for birds to consume. For example, birds often handled M. gracilis for over a minute before consuming or abandoning them, while they consumed each mealworm in a matter of seconds. Although captive blue jays killed nearly all $M$. gracilis prey that we presented to them $(N=37$ of 40$)$, they consumed less than half of those $M$. gracilis after killing them $(N=16$ of 37$)$. Those spiders that were abandoned after being killed had their abdomens flattened and/or pierced, but otherwise their cuticle was intact.

In addition, we recorded one instance during trials where a blue jay regurgitated the cuticle of a $M$. gracilis shortly after consuming it e and then proceeded to pick apart the cuticle further before consuming it again. These results are perhaps unsurprising, given that adult female $M$. gracilis have spiny, sclerotized abdomens. In fact, in the only direct natural observation (to our knowledge) of predation by a bird on a spiny orb-weaving spider, Gasteracantha fornicata, the bird consumed the underside of the abdomen but then left the thickened, dorsal abdomen cuticle behind (T. E. White, personal communication). Furthermore, we know nothing of potential chemical defenses in Micrathena, which might render them unpalatable or otherwise unprofitable to predators. Having chemical defenses could also help explain why so few $M$. gracilis that had been killed were actually consumed by blue jays (Caro \& Ruxton, 2019). Together, these findings suggest that adult female $M$. gracilis possess some combination of traits that could render them unprofitable compared to alternative prey in nature.

Interestingly, we also found no effect of stridulation treatment, nor individual stridulation rate, on the survival of adult female $M$. gracilis under natural conditions. Using CormackJolly-Seber open design models, we found that the best model estimated survival probability varying over time, with spider mass at capture affecting the survival probability at each time step, while resighting probability remained constant. However, the effects of mass on survival over time are not immediately clear (Fig. 4a), likely due to the fact that we measured mass only when first capturing, marking, and releasing an individual spider because of sampling constraints. We also did not find any correlation between spider mass and stridulatory behavior in our field and laboratory assays, so an effect of spider mass on survival is unlikely to be a consequence of an effect of mass on stridulation.

We did find a gradual decline in weekly survival probability over the course of our study, which aligns with the phenology of $M$. gracilis at our field site. Our study began following the peak of mating and lasted until the end of the reproductive season, after which adult females die (Bukowski \& Christenson, 1997b; T. B. Corey, personal observation). The lack of differences in survival probability between silenced and control spiders is further evidence that our experimental manipulations did not influence natural survival. We found three different model structures for estimating resighting probabilities that were within $\triangle \mathrm{AICc}<2$ of a fourth, top model. The resighting probability estimates that we report-estimated at each time step, with an effect of spider body size (Fig. $4 b$ ) - had increasingly large confidence intervals over time. Meanwhile, the second best model $(\triangle \mathrm{AICc}=$ 0.65 ) held resighting probability constant across time steps and treatment groups. Even with this lack of consensus on this aspect of model structure, our results still found no support for stridulation treatment group and/or stridulation rate affecting spider survival 
over time. Therefore, we feel confident in the validity of this negative result and interpreting it in its biological context.

Field studies have demonstrated that the direction and magnitude of selection from predators on conspicuousness (and potentially other antipredator defense traits in general) of univoltine (i.e., one generation of offspring per year) prey can change over the course of the prey's reproductive season, in response to training periods wherein predators learn to avoid unprofitable prey (Mappes, Kokko, Ojala, \& Lindström, 2014). Our laboratory experiment with blue jay predators suggests that adult female $M$. gracilis may be unprofitable prey. Since our field study ran during the latter half of the $M$. gracilis breeding season, adult females were mature and presumably had been interacting with potential predators for at least 1 month at our field site before the study began (T. B. Corey, personal observation). Therefore, if adult female $M$. gracilis are aposematic to relevant predators, and if recognition and avoidance of prey is based on visual cues alone, all adult female $M$. gracilis in a population should be avoided regardless of whether they can stridulate or not following a training period for predators (Mappes et al., 2014). In other words, predators in the field may have already learned to avoid $M$. gracilis, in which case we would not expect to see differences in survival between our treatment groups. Similarly, sympatric predators could have already learned to anticipate and circumvent a potential defensive behavior (Umbers et al., 2019) and would therefore kill sham-treated and silenced M. gracilis with similar effort, again leading the expectation of no difference in survival between silenced and control adult female $M$. gracilis. Performing controlled studies of potential predator learning toward M. gracilis prey (Rojas, Mappes, \& Burdfield-Steel, 2019; Taylor, Amin, Maier, Byrne, \& Morehouse, 2016) or assaying wild predator behavior toward adult female M. gracilis over different points of the season (Mappes et al., 2014; Taylor, Maier, Byrne, Amin, \& Morehouse, 2014) would allow us to tease apart these alternatives.

While many questions remain open, finding their answers might help explain how and why we find such great interspecific variation in putative defense across Micrathena. That is, adult females across the genus Micrathena differ in size, coloration, spination, and microhabitat use - traits that are all known to affect the frequency and outcome of predatorprey interactions in other systems (Ruxton, Allen, Sheratt, \& Speed, 2018). Interestingly, adult female $M$. gracilis lack the red, yellow, and/or orange coloration and elongated abdominal spines found in adult females of many other Micrathena species, which have also been hypothesized to function in antipredator defense (Magalhães \& Santos, 2012; Peckham, 1889). However, adult female $M$. gracilis should otherwise be conspicuous to visual predators, given that they build large webs in open spaces during the daytime (Biere \& Uetz, 1981; T. B. Corey, personal observation). Notably, only adult females of M. gracilis and its sister species Micrathena horrida have widely spaced book lung cover ridges (I. L. F. Magalhães, personal communication; Magalhães \& Santos, 2012), which in M. gracilis forms the stridulatory organ. All other Micrathena have either narrowly spaced book lung cover ridges or smooth book lung covers. Using our laboratory assay, we have collected preliminary data showing that sympatric Micarthena species that differ in book lung cover morphology from $M$. gracilis do not stridulate or perform similar body movements when grasped (see Appendix). Therefore, Micrathena species that differ in morphologies with putative antipredator defense functions may also differ in behavior. 
Ultimately, we found little empirical support for the long-hypothesized antipredator function of stridulation in adult female $M$. gracilis. Stridulation could function in other behavioral contexts (although it has never been reported in numerous studies of M. gracilissee Introduction), or it may not have any current function in M. gracilis (Stankowich, 2011). However, many aspects of stridulation, when considered in context of other potentially relevant traits in female $M$. gracilis, bear similarities to well-studied prey that are aposematic and/or use startle (i.e., deimatic) displays (Rowe \& Halpin, 2013; Umbers et al., 2017). Therefore, we advocate that any future studies consider stridulation by adult female $M$. gracilis along with conspicuousness to visual predators and the potential defenses afforded by spination and sclerotization of the abdomen. Future research on stridulation in male M. gracilis could consider how the absence of these putative physical defenses impact the potential function(s) of stridulation. Such studies should explicitly examine potential mechanisms through which these traits, individually and collectively, impact the frequency and outcomes of predator-prey interactions. Future studies with different predator types will also allow us to determine whether putative defenses differ in their effectiveness against different predators (Corey, 2020; Fabricant \& Smith, 2014). We propose that such studies will shed light on how a trait that is potentially novel in origin but convergent in function arose in this lineage of Micrathena. More broadly, this work would serve as a foundation for studying the evolutionary causes and ecological consequences of antipredator defense trait diversity through a speciose and geographically widespread taxon.

Acknowledgments - We thank Dr. Jeffrey Stevens and the members of the Avian Cognition Lab for allowing us to work with the blue jays in their laboratory. We thank the members of the Hebets Lab and the Behavior Group at the University of Nebraska-Lincoln for their feedback on this manuscript. We thank J. Colton Watts and Dr. Rowan H. McGinley for their help in using the laser Doppler vibrometer. We also thank J. Colton Watts for sharing his extensive knowledge of statistics, his time in reviewing multiple drafts of this manuscript, and his practical experience in working with $M$. gracilis. Drs. Daizaburo Shizuka and William Wagner provided additional feedback on this manuscript. Nicole Graham helped score videos of blue jay predation trials. Sara Hartzell (Lincoln Parks \& Recreation) facilitated the access permits that made our work in Wilderness Park possible and helped us identify promising M. gracilis habitat for collecting spiders and conducting our field experiment. We thank Dr. Glauco Machado for his advice and encouragement in designing and analyzing our field mark-recapture study. We also thank Drs. Gail Stratton and Pat Miller for helping us collect M. gracilis, M. sagittata, and M. mitrata from Mississippi. Funding for this project was provided by the US National Science Foundation Graduate Research Fellowship Program awarded to T.B.C.

\section{References}

Alexander, A. J. (1958). On the stridulation of scorpions. Behaviour, 12(4), 339-352.

Alexander, R. D. (1961). Aggressiveness, territoriality, and sexual behavior in field crickets (Orthoptera: Gryllidae). Behaviour, 17(2), 130-223.

Alexander, R. D. (1962). Evolutionary change in cricket acoustical communication. Evolution, 16(4), 443-467.

Anderson, D. R. (2008). Model based inference in the life sciences: A primer on evidence. New York, NY: Springer Science. 
Aronson, R. B., Heck, K. L., Jr., \& Valentine, J. F. (2001). Measuring predation with tethering experiments. Marine Ecology Progress Series, 214, 311-312.

Barshaw, D. E., Lavalli, K. L., \& Spanier, E. (2003). Offense versus defense: Responses of three morphological types of lobsters to predation. Marine Ecology Progress Series, 256, 171-182.

Bennett-Clark, H. C. (1998). Size and scale effects as constraints in insect sound communication. Philosophical Transactions of the Royal Society B, 353, 407-419.

Biere, J. M., \& Uetz, G. W. (1981). Web orientation in the spider Micrathena gracilis (Araneae: Araneidae). Ecology, 62(2), 336-344.

Blumstein, D. T., \& Armitage, K. B. (1997). Alarm calling in yellow-bellied marmots: I. The meaning of situationally variable alarm calls. Animal Behaviour, 53(1), 143-171. https://doi.org/10.1006/ anbe.1996.0285

Bosher, B. T., Newton, S. H., \& Fine, M. L. (2005). The spines of the channel catfish, Ictalurus punctatus, as an anti-predator adaptation: An experimental study. Ethology, 112, 188-195.

Bouwma, P. E., \& Herrnkind, W. F. (2009). Sound production in Caribbean spiny lobster Panulirus argus and its role in escape during predatory attack by Octopus briareus. New Zealand Journal of Marine \& Freshwater Research, 43, 3-13. https://doi.org/10.1080/00288330909509977

Bradley, R. A. (2012). Common spiders of North America. Oakland, CA: University of California Press.

Brown, W. D., Smith, A. D., Moskalisk, B., \& Gabriel, J. (2006). Aggressive contests in house crickets: Size, motivation and information content of aggressive songs. Animal Behaviour, 72, 225-233. https://doi.org/10.1016/j.anbehav.2006.01.012

Buchler, E. R.,Wright, T. B., \& Brown, E. D. (1981). On the functions of stridulation by the passalid beetle Odontotaenius disjunctus (Coleoptera, Passalidae). Animal Behaviour, 29(2), 483-486.

Bukowski, T. C., \& Christenson, T. E. (1997a). Determinants of sperm release and storage in a spiny orbweaving spider. Animal Behaviour, 53, 381-395.

Bukowski, T. C., \& Christenson, T. E. (1997b). Natural history and copulatory behavior of the spiny orbweaving spider Micrathena gracilis (Araneae, Araneidae). Journal of Arachnology, 25(3), 307-320.

Bukowski, T. C., \& Christenson, T. E. (2000). Determinants of mating frequency in the spiny orbweaving spider, Micrathena gracilis (Araneae: Araneidae). Journal of Insect Behavior, 13(3), 331-352.

Bura, V. L., Rohwer, V. G., Martin, P. R., \& Yack, J. E. (2011). Whistling in caterpillars (Amorpha juglandis, Bombycoidea): Sound-producing mechanism and function. Journal of Experimental Biology, 214, 30-37. https://doi.org/10.1242/jeb/046805

Burger, J. C., Patten, M. A., Rotenery, J. T., \& Redak, R. A. (1999). Foraging ecology of the California gnatcatcher deduced from fecal samples. Oecologia, 120, 304-310.

Caro, T. (2005). Antipredator defenses in birds and mammals. Chicago, IL: University of Chicago Press.

Caro, T., \& Ruxton, G. D. (2019). Aposematism: Unpacking the defences. Trends in Ecology \& Evolution, 34(7), 595-604.

Center for Conservation Bioacoustics. (2016). Raven Lite: Interactive Sound Analysis Software (Version 2.0.1). Ithaca, NY: Cornell Lab of Ornithology. Available from http://ravensoundsoftware.com/.

Chen, P. Z., Carrasco, L. R., \& Ng, P. K. L. (2014). Post-contest stridulation used exclusively as a victory display in mangrove crabs. Ethology, 120, 532-539. https://doi.org/10.1111/eth.12226

Cloudsley-Thompson, J. L. (1995). A review of the anti-predator devices of spiders. Bulletin of the British Arachnological Society, 10(3), 81-96.

Cocroft, R. B. (1999). Parent-offspring communication in response to predators in a subsocial treehopper (Hemiptera: Membracidae: Umbonia crassicornis). Ethology, 105, 553-568. 
Conner, W. E. (2014). Adaptive sounds and silences: Acoustic anti-predator strategies in insects. In B. Hedwig (Ed.), Insect hearing and communication (pp. 65-79). Berlin, Germany: Springer.

Corey, T. B. (2020). Antipredator defense in the spiny orb-weaving spider, Micrathena gracilis. Doctoral dissertation. Lincoln, NE: University of Nebraska-Lincoln. ProQuest Publication no. 28001591.

DeVries, P. J. (1990). Enhancement of symbioses between butterfly caterpillars and ants by vibrational communication. Science, 248(4959), 1104-1106.

Di Giulio, A., Fattorini, S., Moore, W., Robertson, J., \& Maurizi, E. (2014). Form, function and evolutionary significance of stridulatory organs in ant nest beetles (Coleoptera: Carabidae: Paussini). European Journal of Entomology, 111(5), 692-702. https://doi.org/10.14411/eje.2014.083

Dookie, A. L., Young, C. A., Lamothe, G., Schoenle, L. A., \& Yack, J. E. (2017). Why do caterpillars whistle at birds? Insect defence sounds startle avian predators. Behavioural Processes, 138, 58-66. https://doi.org/10.1016/j.beproc.2017.02.002

Elias, D. O., Hebets, E. A., Hoy, R. R., \& Mason, A. C. (2005). Seismic signals are crucial for male mating success in a visual specialist jumping spider (Araneae: Salticade). Animal Behaviour, 69(4), 931-938. https://doi.org/10.1016/j.anbehav.2004.06.024

Elias, D. O., Mason, A. C., \& Hebets, E. A. (2010). A signal-substrate match in the substrate-borne component of a multimodal courtship display. Current Zoology, 56(3), 370-378.

Fabricant, S. A., \& Smith, C. L. (2014). Is the hibiscus harlequin bug aposematic? The importance of testing multiple predators. Ecology and Evolution, 4(2), 113-120. https://doi.org/10.1002/ece3.914

Forsman, A., \& Appelqvist, S. (1999). Experimental manipulation reveals differential effects of colour pattern on survival in male and female pygmy grasshoppers. Journal of Evolutionary Biology, 12, 391-401.

Genung, W. G., \& Green, V. E. (1974). Food habits of the meadowlark in the Everglades in relation to agriculture. Environmental Entomology, 3, 39-42.

Gunnarsson, B. (2008). Bird predation on spiders: Ecological mechanisms and evolutionary consequences. Journal of Arachnology, 35, 509-529.

Gunnarsson, B., \& Wiklander, K. (2015). Foraging mode of spiders affects risk of predation by birds. Biological Journal of the Linnean Society, 115, 58-68.

Heller, K.-G. (1996). Unusual abdomino-alary, defensive stridulatory mechanism in the bushcricket Pantecphylus cerambycinus (Orthoptera, Tettigonioidea, Pseudophullidae). Journal of Morphology, $227,81-86$.

Hill, P. S. M., \& Shadley, J. R. (1997). Substrate vibration as a component of a calling song. Naturwissenschaften, 84, 460-463.

Hinton, H. E., \& Wilson, R. S. (1970). Stridulatory organs in spiny orb-weaver spiders. Journal of Zoology, 162(4), 481-484.

Hodge, M. A. (1987a). Macrohabitat selection by the orb weaving spider, Micrathena gracilis. Psyche, 94, 347-361.

Hodge, M. A. (1987b). Factors influencing web site residence time of the orb weaving spider, Micrathena gracilis. Psyche, 94, 363-371.

Hogstad, O. (1984). Variation in numbers, territoriality and flock size of a goldcrest Regulus regulus population in winter. Ibis, 126, 296-306.

Hrušková-Martišová, M., Pekar, S., \& Gromov, A. (2008). Analysis of the stridulation in solifuges (Arachnida: Solifugae). Journal of Insect Behavior, 21, 440-449.

Jansson, C. (1982). Food supply, foraging, diet and winter mortality in two coniferous forest tit species. Doctoral dissertation. Göteborg, Sweden: University of Götebord. 
Keuper, A., \& Kühne, R. (1983). The acoustic behavior of the bushcricket Tettigonia cantans. II. Transmission of airborne-sound and vibration signals in the biotope. Behavioural Processes, 8(2), 125-145.

Large, S. I., \& Smee, D. L. (2013). Biogeographic variation in behavioral and morphological responses to predation risk. Oecologia, 171, 961-969. https://doi.org/10.1007/s00442-012-2450-5

Lebreton, J.-D., Burnham, K. P., Clobert, J., \& Anderson, D. R. (1992). Modelling survival and testing biological hypotheses using marked animals: A unified approach with case studies. Ecological Monographs, 62, 67-118.

Lessells, C. M., \& Boag, P. T. (1987). Unrepeatable repeatabilities: A common mistake. Auk: Ornithological Advances, 104(1), 116-121.

Levi, H. W. (1978). The American orb-weaver genera Cophepeira, Micrathena and Guteracantha north of Mexico (Araneae, Araneidae). Bulletin of the Museum of Comparative Zoology, 148, 417-442.

Lewis, E. E., \& Cane, J. H. (1984). Stridulation as a primary anti-predator defence of a beetle. Animal Behaviour, 40(5), 1003-1004.

Líznarova, E., Sentenska, L., Štáhlavsky, F., \& Pekár, S. (2018). Stridulation can suppress cannibalism in a specialised araneophagous predator. Behavioral Ecology and Sociobiology, 72, 127. https://doi.org/ 10.1007/s00265-018-2541-3

Magalhães, I. L. F., \& Santos, A. J. (2012). Phylogenetic analysis of Micrathena and Cahetacis spiders (Araneae: Araneidae) reveals multiple origins of extreme sexual size dimorphism and long abdominal spines. Zoological Journal of the Linnean Society, 166, 14-53.

Manser, M. B. (2001). The acoustic structure of suricates' alarm calls varies with predator type and the level of response urgency. Proceedings of the Royal Society B: Biological Sciences, 268(1483), 23152324. https://doi.org/10.1098/rspb/2001/1773

Mappes, J., Kokko, H., Ojala, K., \& Lindström, L. (2014). Seasonal changes in predator community switch the direction of selection for prey defences. Nature Communications, 5, Article 5016. https://doi .org/10.1038/ncomms6016

Masters, W. M. (1979). Insect disturbance stridulation: Its defensive role. Behavioral Ecology and Sociobiology, 5(2), 187-200.

Masters, W. M. (1980). Insect disturbance stridulation: Characterization of airborne and vibrational components of the sound. Journal of Comparative Physiology, 135, 259-268.

Masters, W. M., Tautz, J., Fletcher, N. H., \& Markl, H. (1983). Body vibration and sound production in an insect (Atta sexdens) without specialized radiating structures. Journal of Comparative Physiology, 150(2), 239-249.

Olofsson, M., Jakobsson, S., \& Wiklund, C. (2012). Auditory defence in the peacock butterfly (Inachis io) against mice (Apodemus flavicollis and A. sylvaticus). Behavioral Ecology and Sociobiology, 66, 209215. https://doi.org/10.1007/s00265-011-1268-1

Patek, S. N. (2001). Spiny lobsters stick and slip to make sound. Nature, 411, 153-154.

Peckham, E. G. (1889). Protective resemblances in spiders. Occasional Papers of the Natural History Society of Wisconsin, 1(2), 61-113.

Polhemus, J. T. (1994). Stridulatory mechanisms in aquatic and semiaquatic Heteroptera. Journal of the New York Entomological Society, 102(2), 270-274.

Pomini, A. M., Machado, G., Pinto-da-Rocha, R., Macías-Ordóñez, R., \& Marsaioli, A. J. (2010). Lines of defense in the harvestman Hoplobunus mexicanus (Arachnida, Opiliones): Aposematism, stridulation, thanatosis, and irritant chemicals. Biochemical Systematics and Ecology, 38, 300-308.

Puntilla, R. I., Martin, C. W., \& Valentine, J. F. (2012). Measuring predation with a new design of submersible chronographic timer. Bulletin of Marine Science, 88(4), 1115-1122. 
R Core Team. (2019). R: A language and environment for statistical computing. Vienna, Austria: R Foundation for Statistical Computing. https://www.R-project.org

Ratcliffe, J. M., \& Nydam, M. L. (2008). Multimodal warning signals for a multiple predator world. Nature, 455, 96-99. https://doi.org/10.1038/nature07087

Riechert, S. E., \& Hedrick, A. V. (1990). Levels of predation and genetically based anti-predator behaviour in the spider Agenelopsis aperta. Animal Behaviour, 40, 679-687.

Roces, F., \& Manrique, G. (1995). Different stridulation vibrations during sexual behaviour and disturbance in the blood-sucking bug Triatoma infestans (Hemiptera: Reduviidae). Journal of Insect Physiology, 42(3), 231-238.

Roces, F., Tautz, J., \& Hölldobler, B. (1993). Stridulation in leaf-cutting ants. Naturwissenschaften, 80, 521-524.

Rojas, B., Mappes, J., \& Burdfield-Steel, E. (2019). Multiple modalities in insect warning displays have additive effects against wild avian predators. Behavioral Ecology and Sociobiology, 73, Article 37. https://doi.org/10.1007/s00265-019-2643-6

Rovner, J. S. (1975). Sound production by nearctic wolf spiders: A substratum-coupled stridulatory mechanism. Science, 190(4221), 1309-1310. https://doi.org/10.1126/science/190.4221.1309

Rowe, C., \& Halpin, C. (2013). Why are warning displays multimodal? Behavioral Ecology and Sociobiology, 67(9), 1425-1439.

Rundus, A. S., Santer, R. D., \& Hebets, E. A. (2010). Multimodal courtship efficacy of Schizocosa retrorsa wolf spiders: Implications of an additional signal modality. Behavioral Ecology, 21(4), 701707. https://doi.org/10.1093/beheco/arq042

Ruxton, G. D., Allen, W. L., Sheratt, T. N., \& Speed, M. P. (2018). Avoiding attack: The evolutionary ecology of crypsis, aposematism, and mimicry (2nd ed). Oxford, UK: Oxford University Press.

Schneider, C. A., Rasband, W. S., \& Eliceiri, K. W. (2012). NIH image to ImageJ: 25 years of image analysis. Nature Methods, 9(7), 671-675.

Schoener, T. W., \& Toft, C. A. (1983). Spider populations: Extraordinarily high densities on islands without top predators. Science, 219(4590), 1353-1355.

Shear, W. A. (1970). Stridulation in Acanthophrynus coronatus (butler) (amblypygi, tarantulidae). Psyche, 77(2), 181-183.

Staaterman, E. R., Claverie, T., \& Patek, S. N. (2009). Disentangling defense: The function of spiny lobster sounds. Behaviour, 147, 235-258.

Stankowich, T. (2011). Armed and dangerous: Predicting the presence and function of defensive weaponry in mammals. Adaptive Behavior, 20(1), 32-43. https://doi.org/10.1177/1059712311426798

Tautz, J., Roces, F., \& Hölldobler, B. (1995). Use of a sound-based vibratome by leafcutting ants. Science, 267(5194), 84-87.

Taylor, L. A., Amin, Z., Maier, E. B., Byrne, K. J., \& Morehouse, N. I. (2016). Flexible color learning in an invertebrate predator: Habronattus jumping spiders can learn to prefer or avoid red during foraging. Behavioral Ecology, 27(2), 520-529.

Taylor, L. A., Maier, E. B., Byrne, K. J., Amin, Z., \& Morehouse, N. I. (2014). Colour use by tiny predators: Jumping spiders show colour biases during foraging. Animal Behaviour, 90, 149-157.

Toju, H., \& Sota, T. (2006). Imbalance of predator and prey armament: Geographic clines in phenotypic interface and natural selection. The American Naturalist, 167(1), 105-117.

Uetz, G. W., \& Stratton, G. E. (1982). Acoustic communication and reproductive isolation. In J. S. Rovner, \& P. N. Witt (Eds.), Spider communication: Mechanisms and ecological significance (pp. 123159). Princeton, NJ: Princeton University Press. 
Uhl, G., \& Schmitt, M. (1996). Stridulation in Palpimanus gibbulus Dufour (Araneae: Palpimanidae). In V. Mahnert (Ed.), Proceedings of the XIIIth International Congress of Arachnology, Geneva, 3-8 September 1995, Revue Suisse de zoologize: annales de la Société Suisse de Zoologie et du Muséum d'Histoire Naturelle de la Ville de Genéve (Vols. 1 and 2, pp. 649-660). Geneva, Switzerland: Geneva Museum, Swiss Zoological Society.

Umbers, K. D. L., De Bona, S., White, T. E., Lehtonen, J., Mappes, J., \& Endler, J. A. (2017). Deimatism: A neglected component of antipredator defence. Biology Letters, 13(4), 20160936.

Umbers, K. D. L., White, T. E., De Bona, S., Haff, T., Ryeland, J., Drinkwater, E., et al. (2019). The protective value of a defensive display varies with the experience of wild predators. Scientific Reports, 9, Article 463. https://doi.org/10.1038/s41598-018-36995-9

Vanderhoff, E. N., Byers, C. J., \& Hanna, C. J. (2008). Do the color and pattern of Micrathena gracilis (Araneae: Araneidae) attract prey? Examination of the prey attraction hypothesis and crypsis. Journal of Insect Behavior, 21, 469-475. https://doi.org/10.1007/s10905-008-9142-3

White, G. (2020). Program MARK. phidot.org/software/mark/index.html

\section{Appendix}

\section{Potential Predators of Micrathena gracilis}

Despite many hours of field observations made during the course of this study, we never directly observed predation on M. gracilis in nature. This also includes $65 \mathrm{~h}$ of focal video recordings of female $M$. gracilis on webs made during mark-recapture surveys. Therefore, our best inferences for potential predators of $M$. gracilis come from anecdotes and extrapolations from studies/observations on related spider groups. We describe our justification for using blue jays as a candidate avian predator in the Introduction. Micrathena are found noticeably less often, if at all, in the nests of several species of spider-specialist mud-dauber wasps, even in areas where Micrathena are abundant (Gonzalez \& Vasconcellos-Neto, 2005; Muma \& Jeffers, 1945). The elongated abdominal spines of Micrathena are hypothesized to have evolved under selection from mud-dauber wasp predators as an antipacking mechanism (i.e., to make spiders difficult/inefficient to provision to larvae developing in mud nest cells; Elgar \& Jebb,1999; Magalhães \& Santos, 2012). On the other hand, some species of mud-dauber wasp in the genus Sceliphron appear to specialize on Micrathena prey in some areas (Sceliphron spp.: Gonzalez-Bustamante, 1994; Sceliphron fistularium in Brazil: Camillo, 2002). We observed a jumping spider (Paraphidippus aurantia) preying on an adult female $M$. gracilis under seminatural conditions (a field enclosure at our field site), and jumping spiders are known to prey on other species of orb-weaving spiders (Seah \& $\mathrm{Li}$, 2001). Micrathena gracilis might also be potential prey for mammals and reptiles that prey on small arthropods, such as mice (Olofsson, Jakobsson, \& Wiklund, 2012) and lizards (Schoener \& Toft, 1983).

\section{Validation of Sham and Silencing Treatments}

We validated our sham- and stridulation-silencing treatments using nail polish following the same protocol for our laboratory stridulation assay described in the main text. We first conducted preliminary trials to confirm that applying nail polish to the book lung covers was sufficient to silence sound production from stridulation. We held spiders $(N=5)$ by 
hand next to a microphone (Sennheiser ME 64, with a TASCAM DR-05 audio recorder) and visually confirmed whether they performed the movements associated with stridulation. We then listened to audio recordings to confirm that no sound had been produced for those spiders that we had observed attempting to stridulate. We repeated this process with control spiders (nail polish applied to the posterior abdomen, $N=5$ ) to confirm that spiders attempted to stridulate and still produced the sound associated with stridulating. Furthermore, we kept spiders in individual deli dishes lined with moist paper towel for $24 \mathrm{~h}$ immediately following application of nail polish to observe adverse effects on behavior or health of $M$. gracilis.

We later validated our treatments using our laboratory assay for quantifying stridulatory behavior and acoustics as well. Adult female $M$. gracilis given our sham and silencing treatments ( $N=12$ sham, 12 silenced) could still attempt to stridulate. We observed natural sound production from control spiders, and limited, if any, sound production from silenced spiders. There was no significant difference in the presence of stridulation in untreated, silenced, and control (sham-treated) M. gracilis in our laboratory assay (binomially distributed generalized linear model: $\left.\chi^{2}{ }_{2}=-2.883, P=0.24\right)$. In fact, the proportions of silenced and control M. gracilis that stridulated were the same (5 of 12 individuals per treatment).

We also confirmed that sham- and stridulation-silencing treatments using beeswax (for our laboratory predation experiment with blue jays) were effective and harmless to M. gracilis. As with our nail polish-based treatments, we found that silenced spiders indeed performed the movements associated with stridulation but did not produce sound, but control spiders produced the sounds and movement associated with stridulation. Therefore, in our laboratory and field experiments, there should be no differential effects on stridulatory behavior per se between sham and silenced treatment groups-only the production of sound and vibrations via stridulation should be affected.

\section{Stridulation Laboratory Assay with Micrathena sagittata and Micrathena mitrata}

We repeated our laboratory assay for stridulatory behavior to explore whether Micrathena that differ in book lung cover morphology (part of the stridulatory organ in M. gracilis) also differ in their ability to stridulate. We collected adult female $M$. sagittata and M. mitrata from Oxford, Mississippi, USA. These congeners can be found sympatrically with M. gracilis in the continental United States in multiple parts within each species' range (Levi, 1978). Micrathena sagittata do not have ridges on their book lung covers, so we predicted that they would not stridulate nor produce any movements associated with stridulating. Micrathena mitrata have narrowly spaced book lung cover ridges, so we considered it possible that they could stridulate but predicted that it would differ qualitatively from stridulation in M. gracilis if they could. Along with M. gracilis, which has widely spaced book lung cover ridges (Magalhães \& Santos, 2012), these species represent the three categories of book lung morphology that have been described within Micrathena (Magalhães \& Santos, 2012). None of the M. sagittata $(N=5)$ and none of the M. mitrata $(N=5)$ stridulated in our laboratory assay. Anecdotally, none of these spiders stridulated when being prepared for the assay, or when being handled during the course of other laboratory experiments ( $N=13$ M. sagittata, $N=13$ M. mitrata; T. B. Corey \& E. A. Hebets, personal observations). 

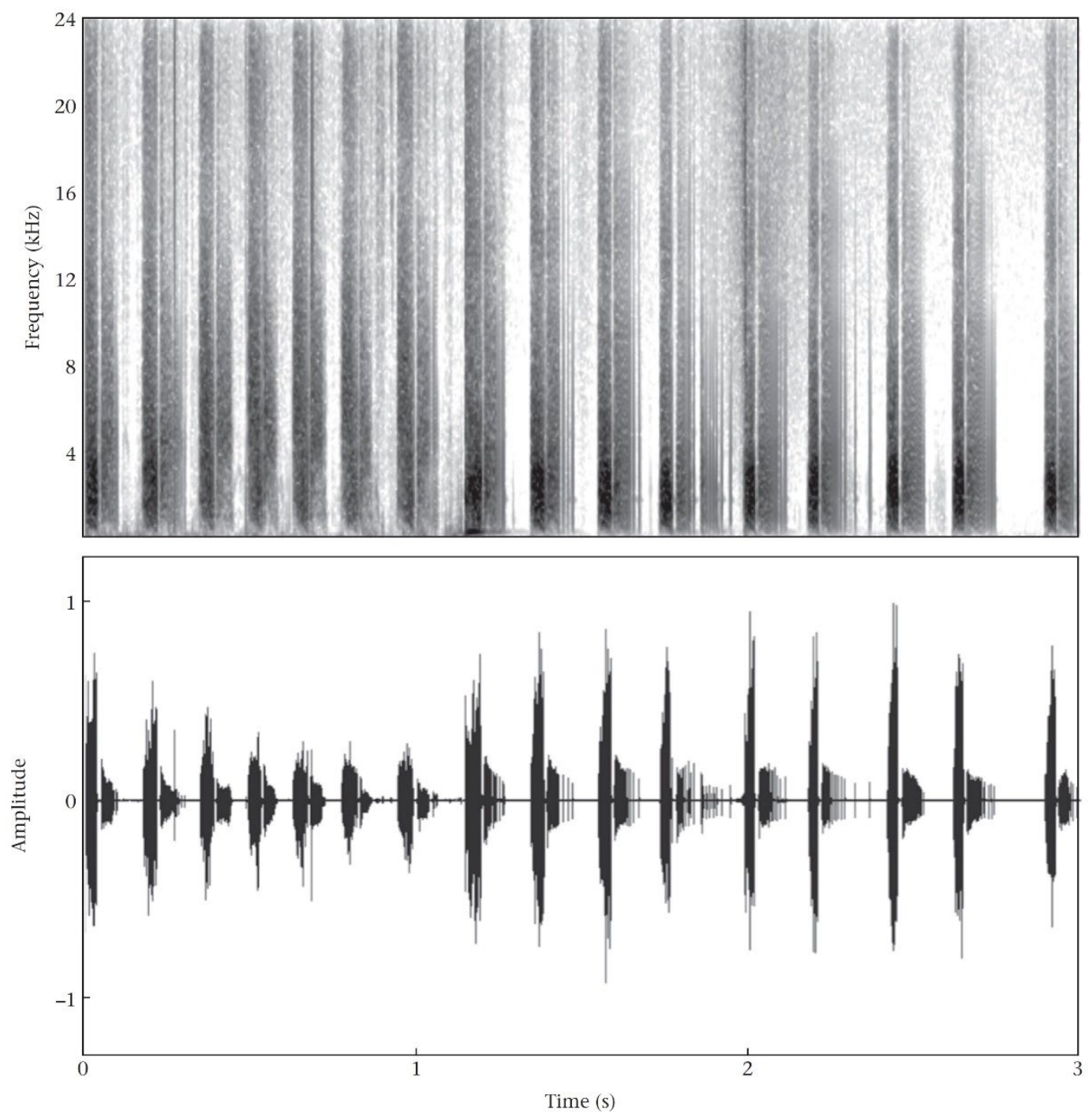

Figure A1. Exemplar spectrogram and waveform of stridulation by a male $\mathrm{Mi}$ crathena gracilis, recorded using a laser Doppler vibrometer. Amplitude units were standardized as in Figure 2 (see Methods, Experiment 1, for details). We could not adequately record the airborne sound produced by male stridulation using a microphone.

Video S1. Laboratory assay of stridulatory behaviour in adult Micrathena gracilis. An experimenter applied a tactile stimulus simulating predator attack to individual M. gracilis in four regular intervals (see Methods, Experiment 1). Cuticleborne vibrations were recorded using a laser Doppler vibrometer into a Focusrite Scarlett Solo interface and CaptureSync software. Audio presented here is recorded from the laser Doppler vibrometer. 